\title{
Understanding and Interpreting Laser Diagnostics in Flames: A Review of Experimental Measurement Techniques
}

\author{
Michael J. Evans* and Paul R. Medwell \\ School of Mechanical Engineering, The University of Adelaide, Adelaide, SA, Australia
}

There is a wealth of existing experimental data of flames collected using laser diagnostics. The primary objective of this review is to provide context and guidance in interpreting these laser diagnostic data. This educational piece is intended to benefit those new to laser diagnostics or with specialization in other facets of combustion science, such as computational modeling. This review focuses on laser-diagnostics in the context of the commonly used canonical jet-in-hot-coflow (JHC) burner, although the content is applicable to a wide variety of configurations including, but not restricted to, simple jet, bluff body, swirling and stratified flames. The JHC burner configuration has been used for fundamental studies of moderate or intense low oxygen dilution (MILD) combustion,

\section{OPEN ACCESS}

Edited by:

Alessandro Parente,

Université libre de Bruxelles, Belgium

Reviewed by:

Dirk J. E. M. Roekaerts, Delft University of Technology, Netherlands

Giancarlo Sorrentino,

University of Naples Federico II, Italy

${ }^{*}$ Correspondence:

Michael J. Evans

m.evans@adelaide.edu.au

Specialty section:

This article was submitted to Thermal and Mass Transport,

a section of the journal

Frontiers in Mechanical Engineering

Received: 30 April 2019 Accepted: 15 November 2019 Published: 29 November 2019

Citation:

Evans MJ and Medwell PR (2019) Understanding and Interpreting Laser Diagnostics in Flames: A Review of Experimental Measurement

Techniques. Front. Mech. Eng. 5:65 doi: 10.3389/fmech.2019.00065 autoignition and flame stabilization in hot environments. These environments emulate sequential combustion or exhaust gas recirculation. The JHC configuration has been applied in several burners for parametric studies of MILD combustion, flame reaction zone structure, behavior of fuels covering a significant range of chemical complexity, and the collection of data for numerical model validation. Studies of unconfined JHC burners using gaseous fuels have employed point-based Rayleigh-Raman or two-dimensional Rayleigh scattering measurements for the temperature field. While the former also provides simultaneous measurements of major species concentrations, the latter has often been used in conjunction with planar laser-induced fluorescence (PLIF) to simultaneously provide quantitative or qualitative measurements of radical and intermediary species. These established scattering-based thermography techniques are not, however, effective in droplet or particle laden flows, or in confined burners with significant background scattering. Techniques including coherent anti-Stokes Raman scattering (CARS) and non-linear excitation regime two-line atomic fluorescence (NTLAF) have, however, been successfully demonstrated in both sooting and spray flames. This review gives an overview of diagnostics techniques undertaken in canonical burners, with the intention of providing an introduction to laser-based measurements in combustion. The efficacy, applicability and accuracy of the experimental techniques are also discussed, with examples from studies of flames in JHC burners. Finally, current and future directions for studies of flames using the JHC configuration including spray flames and studies and elevated pressures are summarized.

Keywords: laser diagnostics, jet in hot coflow (JHC), vitiated coflow burner (VCB), autoignition, planar thermography, moderate or intense low oxygen dilution (MILD) combustion, laser-induced fluorescence (LIF) 


\section{INTRODUCTION}

Laser diagnostics are a well-established cornerstone of experimental combustion research. Laser diagnostics facilitate the measurement of temperature, velocity and a variety of chemical species in flames. Accurate experimental measurements are a unique source of invaluable real data to bolster the fundamental understanding of combustion. Laser-based measurements can provide data encompassing a broad range of length and temporal scales of flames. Furthermore, experiments are an essential tool for further advances in computational modeling, both by providing data for validation as well as identifying realistic boundary conditions for numerical studies.

Laser-based diagnostics enable measurements of flames without the need for intrusive sampling probes or thermocouples which disturb the flow-field of a flame and may have additional catalytic effects (Eckbreth, 1996). Not only can physical probes affect the flames they are measuring, they have limited spatial and temporal resolutions which limits their efficacy in turbulent flames. Lasers, however, can provide virtually instantaneous measurements at spatial resolutions of similar order of magnitude to Kolmogorov length-scales.

Flames in hot and diluted coflows are analogous to practical implementations of fuel issuing into preheated and oxygenvitiated environments such as found in furnaces with exhaust gas recirculation (EGR) (Dally et al., 2004), modern diesel engines (Yao et al., 2009), and sequential or inter-turbine burners (ITBs) for gas turbines (Sturgess et al., 2005; Döbbeling et al., 2007; Perpignan et al., 2018). Fundamental studies of these flames have not only provided significant insight into autoignition processes, but have been used to generate extensive datasets in simplified configurations for validating turbulence-chemistry interaction models for numerical modeling of combustion systems. Fundamental studies of laminar and turbulent jet flames issuing into high temperature, low oxygen environments have been undertaken in jet in hot coflow (JHC) burners (Dally et al., 2002; Medwell et al., 2007, 2008; Oldenhof et al., 2010, 2011; Oldenhof et al., 2012; Medwell and Dally, 2012a; Sepman et al., 2013; Ye et al., 2016, 2017, 2018; Evans et al., 2017b, 2019a,b; Kruse et al., 2019), hot cross-flow burners (Sidey and Mastorakos, 2017), vitiated coflow burners (VCBs) (Cabra et al., 2002, 2005; Gordon et al., 2008, 2009; Macfarlane et al., 2018, 2019; Ramachandran et al., 2019), and partially premixed jet burners (PPJBs) (Dunn et al., 2007a; Dunn et al., 2009), as have spray flames in hot coflow burners (Correia Rodrigues et al., 2015a,b; Wang et al., 2019b). In each case, fresh fuel issues from a jet into a stream of hot gas generated by lean premixed flames, resulting in $\lesssim 15 \% \mathrm{O}_{2}$ (by vol.). The remainder of the oxidant streams are typically composed of $\mathrm{H}_{2} \mathrm{O}, \mathrm{CO}_{2}$, $\mathrm{N}_{2}$, and minor species. As each of these burners share this common jet-and-annular-coflow-burner configuration, they will all be referred to herein as JHC burners for ease of readability. Research undertaken in JHC burners has focussed on ignition processes in hot and diluted environments, particularly toward understanding high temperature autoignition (Mastorakos, 2009), and ignition processes in the moderate or intense low oxygen dilution (MILD) combustion regime (Cavaliere and de Joannon, 2004). Combustion in the MILD regime features homogeneous temperature distributions, low peak temperatures and temperature fluctuations, and offers reduced formation of soot and $\mathrm{NO}_{\mathrm{x}}$. Furthermore, fundamental studies of the MILD combustion regime in JHC burners often feature order unity Damköhler with reduced chemical timescales approaching those of the turbulent jet. These characteristics of low temperature increases, and subsequently low radical species concentrations, lead to the requirement of highly sensitive temperature and species measurements in studying MILD combustion. Fortuitously, the often soot-free flames allow a variety of different laser diagnostics.

Experimental studies of diffusion flames in hot and vitiated conditions similar to those encountered in MILD combustion have revealed the existence of "weak-to-strong" transition points (Medwell et al., 2008; Medwell and Dally, 2012a; Evans et al., 2015a, 2019c). This occurs when a weakly reacting, attached diffusion undergoes a rapid increase in temperature and reaction zone thickness (Medwell et al., 2008; Medwell and Dally, 2012a). These transition points, which will be addressed at length in section 7 , are critical to the stabilization and structure of flames emanating into hot and vitiated environments, and the capacity to predict this phenomenon is essential for practical, novel implementations of MILD combustion and similar low-emissions combustion technologies. Such improved understanding these transitions-and the structure of the upstream flames leading to their formation-may be achieved through targeted laser-diagnostics studies and subsequently validated, complementary numerical modeling. The high fidelity data that laser diagnostics can provide allows for the detailed study of reactive structures across the broad range of spatial and temporal scales in different optically-accessible JHC burners and reactors (Plessing et al., 1998; Cabra et al., 2002, 2005; Dally et al., 2002; Medwell et al., 2007, 2008; Gordon et al., 2008, 2009; Oldenhof et al., 2010, 2011; Oldenhof et al., 2012; Medwell and Dally, 2012a; Sepman et al., 2013; Sorrentino et al., 2015, 2016; Ye et al., 2016, 2017, 2018; Evans et al., 2017b, 2019a,b; Sidey and Mastorakos, 2017; Macfarlane et al., 2018, 2019; Kruse et al., 2019; Ramachandran et al., 2019). Laser diagnostics a provide means to investigate the small-scale and distributed reaction zones in macroscopically-near-homogeneous MILD combustion conditions. Such research not only improves the understanding of the behavior of these regimes, but provide reference cases and motivation for complementary numerical studies (Ihme and See, 2011; de Joannon et al., 2012; Ihme et al., 2012; Minamoto and Swaminathan, 2014; Minamoto et al., 2014; Sabia et al., 2015; Sidey and Mastorakos, 2015; Medwell et al., 2016; Evans et al., 2017a,b, 2019c; Sorrentino et al., 2017; Doan and Swaminathan, 2019; Wang et al., 2019a) which could otherwise be performed in isolation or target conditions with either limited practical applicability or data for model validation.

This paper presents a review of laser diagnostics applicable to studies of flames in canonical burners-particularly focusing on the JHC configuration-for the benefit of readers new to, or outside of, this field. Despite this particular focus on JHC burners, the techniques and discussions are also relevant to simple jet, bluff body, swirling and stratified flames. The paper will initially 
provide a brief background on laser-based experimentation, before discussing challenges of data quantification in laserdiagnostics. Having provided the requisite background, the paper then discusses the techniques used for velocity, species and temperature measurements of flames stabilized in JHC burners, the technical challenges they present and the findings from these studies. Finally, future diagnostics needed for better understanding flames in JHC burners will be discussed.

\section{PRINCIPLES OF LASER DIAGNOSTICS}

\subsection{Principles of Light-Matter Interactions}

Light can interact with matter in a range of different ways. Light can scatter off of atoms, molecules and particles in predictable ways, or-on a quantum scale-a photon can be absorbed and a new photon emitted. These new photons may have the same energy as the original (and thus be at the same wavelength), may have less energy or, in some cases, more energy. Detecting these emitted photons produces a quantifiable "signal." The total number of these detected photons and their energies correspond to the intensity of the signal and its spectral response, respectively. The relationship between photon energy $(E)$ and its wavelength $(\lambda)$ or frequency $(f)$ is given by Equation (1), where $h$ is Planck's constant and $c$ is the speed of light:

$$
E=\frac{h \cdot c}{\lambda}=h \cdot f
$$

Equation (1) highlights that shorter wavelength photons have more energy than longer wavelength photons, i.e., ultraviolet (UV) photons have more energy than visible photons. Similarly, photon energy decreases from UV to blue to green to red to infrared light. Relevant UV wavelengths for combustion diagnostics lie between $\sim 190$ and $400 \mathrm{~nm}$ and visible light is considered as 400 and $700 \mathrm{~nm}$.

Scattering of light from a dielectric particle (with effective diameter $d_{p}$ ) is dependent on the wavelength of the incident light. Large particles (e.g., droplets or solid particles) scatter light according to the complex Mie theory (Eckbreth, 1996). Mie scattering is a far-field solution of Maxwell's equations in spherical coordinates, with light emanating from the surface of the particle of size $d_{p}$. This results in directiondependent scattering described by an infinite series of Legendre polynomials. Mie scattering is typically several orders of magnitude greater than the related phenomenon of Rayleigh scattering and is the underlying principle for techniques such as particle image velocimetry. Because of this disparate intensity, excessive Mie scattering may also prohibit other scattering measurements with lower signal levels, such as Rayleigh scattering.

Small, polarizable particles (e.g., atoms or molecules) may scatter light according to Rayleigh scattering. This follows a first-order approximation for particles much smaller than the wavelength of incident light. Scattering in any given direction scales as $d_{p}^{6} \cdot \lambda^{-4}$ and is a function of the effective refractive index of the particle. At molecular level, Rayleigh scattering occurs when a molecule absorbs a photon, increasing its internal

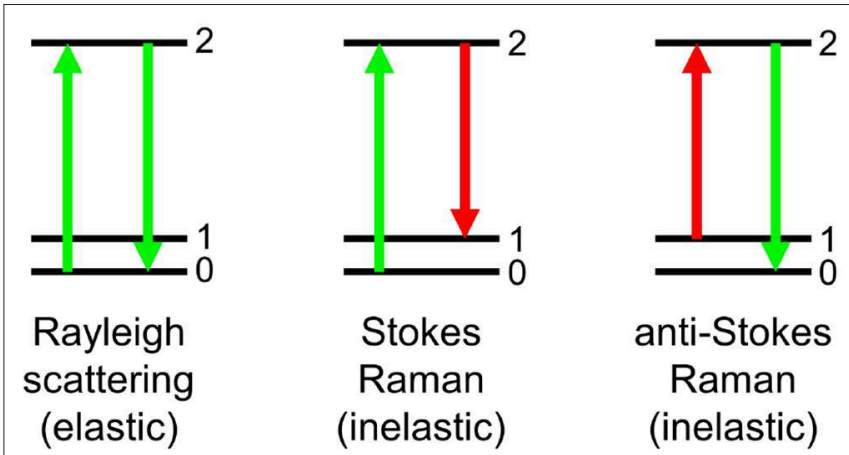

FIGURE 1 | Three-level model of excitation levels, showing Rayleigh (left) and Raman (Stokes, center, and anti-Stokes, right) processes. Note that the highest energy levels in these models need not necessarily correspond to stable atomic or molecular vibrational states.

energy, and then emits a photon at the same wavelength. This is shown using a simplified three-level energy diagram in Figure 1, where " 0 " is the "ground state." The same simplified model of excitation may also be applied to individual atoms. The amount of Rayleigh scattering due to individual molecular species can be quantified and characterized by its Rayleigh cross-section $(\sigma)$. Values of $\sigma$ are tabulated for common gases in various sources (Namer and Schefer, 1985; Eckbreth, 1996; Masri et al., 1996; Kohse-Höinghaus and Jeffries, 2002; Sutton and Driscoll, 2004). The intensity of scattered light from a stationary molecule is a function of the direction compared to the incoming light. Following calibration and estimation of the gas composition, this can provide the local number of molecules per unit volume (number density, $n$ ) and, hence, local temperature based on the ideal gas law. In non-reacting flows, results from this method can be accurate to within 1\% (Arndt et al., 2019).

Spontaneous Raman scattering is a non-linear analog of Rayleigh scattering, but produces signals approximately three orders of magnitude weaker. Whereas Rayleigh scattering emits only at the incident wavelength, Raman scattering from an atom or molecule in its ground state emits a lower energy photon corresponding to relaxation to an excited energy state (see Figure 1). This emitted photon is at a longer wavelength and the process is referred to as Stokes Raman scattering. Referring again to Figure 1, the opposite of this process-where a higher energy photon is emitted-is termed anti-Stokes Raman scattering. This requires atoms or molecules to already be in an excited state. Although this occurs in flames, only a small fraction of molecules are excited at flame temperatures, resulting in significantly weaker signals than Stokes Raman. Optical pumping prior to anti-Stokes Raman scattering excites a larger fraction of atoms or molecules than from thermal energy alone, and forms the conceptual basis of techniques such as coherent anti-Stokes Raman scattering (CARS) thermography (see section 6). Raman, Rayleigh and Mie scattering are all effectively instantaneous processes and measurement signals are dependent on the pulse energy, rather than the pulse duration although this may affect the background signal from secondary scattering or optical breakdown (plasma formation) (Eckbreth, 1996; Kojima and 
Nguyen, 2002). This is more prevalent at higher pressures where species number densities are higher (Eckbreth, 1996; Jiang et al., 2017).

Energy levels of atoms/molecules probed in optical diagnostics may be "virtual" (as is the case for Rayleigh and Raman scattering), or allowable energy levels (also termed "resonant," as is the case in fluorescence techniques). Atomic and molecular energy levels are conceptually similar, with atomic energy levels corresponding to quasi-stable electron orbital shells and the latter being allowable states for combinations of molecular rotations and vibrations. Molecular levels correspond to allowable rotational energies of the molecules about each of its axes and the vibrational energies of the intramolecular bonds. Molecular excitation states are often closely grouped, with the discrete energies being a function of both the rotational and vibrational state. Probing these states by exciting molecules to a given energy level results in the emission of a lower energy, longer wavelength photon as the molecule cascades to its ground states. This process is known as laser-induced fluorescence (LIF) and is one of the most widely used approaches for detecting certain species within flames (see section 4). A similar process of exciting atoms, albeit from both the ground and thermally excited states (analogous to Stokes and anti-Stokes Raman scattering), is two-line atomic fluorescence (TLAF) which may be used for thermography (see section 6).

\subsection{Laser Operation}

Lasers supply "coherent" light centered about a given wavelength $(\sim 180-10,000 \mathrm{~nm})$, with a precision of $\lesssim 0.1 \mathrm{~nm}$, and often much less. This distribution in wavelength is described as the laser "linewidth." Emitted photons from lasers are generated from atoms or molecules in a "gain medium" excited through "optical pumping." High energy photons are absorbed and lower energy (longer wavelength) photons are emitted as the atom or molecule returns to its ground state. The output wavelength of a laser is subsequently a property of the gain medium and, additionally, properties of the optical components used in the construction of the laser.

Lasers used for diagnostics of flames stabilized in JHC burners are often flashlamp-pumped solid-state lasers or high energy dye lasers. Lasers for diagnostics are often "pulsed" such that the laser energy is delivered as short ( $\lesssim 10 \mathrm{~ns})$, high energy pulses (or "shots") at repetition rates between $10 \mathrm{~Hz}$ and $10 \mathrm{kHz}$. These brief periods of illumination enables the image to effectively "freeze the flow" and capture an image at one very specific instant in time. Similarly, multiple laser diagnostic techniques used "simultaneously" often employ pulsed lasers separated by $\sim 100 \mathrm{~ns}$, which is much slower than the flow or chemical timescales.

Many diagnostic techniques require specific unique wavelength light required to excite energy transitions in atoms and molecules of interest. These techniques necessitate the use of lasers which can be tuned to preselected specific wavelengths. Dye lasers are used to provide a tunable source of high energy laser pulses, spanning from deep UV to mid-IR $(\sim 190 \mathrm{~nm}$ to $\sim 4.5 \mu \mathrm{m}$, respectively). Dye lasers use specific dyes to fluoresce at a desired wavelength when pumped with shorter wavelength light. Dyes themselves are often organic solids which are dissolved in solvents, such as ethanol, for use. Individual dyes have different effective lifetimes and, as a general rule-of-thumb, dyes pumped by UV lasers must be replaced significantly more often than those pumped with visible wavelengths. Not all wavelengths may be efficiently obtained by direct dye pumping and, in these cases, non-linear frequency doubling or two-mixing wave processes are employed. For example, the former is often used to generate the wavelengths near $283 \mathrm{~nm}$ for OH-LIF (discussed in sections 2.4 and 4), the latter used to generate the $410 \mathrm{~nm}$ laser for indium TLAF (section 6) and both are used in series to generate the $226 \mathrm{~nm}$ beam for NO-LIF studies.

An important consideration beyond laser wavelength and pulse energy is the intensity profile emanating from the laser. These profiles may be approximated as Gaussian, triangular, or "top-hats" (Gordon et al., 2008; Dunn and Masri, 2010), but are often significantly more complex due to imperfections in mirrors and sheet-forming-optics, and vary between individual laser pulses (i.e., shot-to-shot). Variations in beam profile may also be caused by variations in refractive index, inherent in flames, which result in refraction of the beam termed "beamsteering" (Kruse et al., 2018). As such, beam profiles may also be measured for each individual shot. This may be performed using a dedicated beam profiling camera, imaging fluorescence or scattering from a cuvette or glass sheet, or with a reference burner either in-plane or using a portion of the incident light sheet.

\subsection{Data Collection and Processing}

Due to the relatively low signal level, often only over very brief periods of time, scientific cameras used in combustion diagnostics are often intensified CCD (ICCD) cameras, although intensified scientific CMOS (sCMOS) cameras are becoming more prevalent as this technology matures. For simplicity, only CCD cameras will be referred to, though the operating principle is the same. Optical intensifiers operate by focusing photons onto a light-sensitive photocathode (e.g., through a camera lens), which in-turn releases electrons. Photocathode materials have specific sensitivities to different wavelengths of light and so must be appropriately selected as part of experimental design. A microchannel plate (MCP) behind the photocathode acts as an amplifier when a voltage is applied, accelerating electrons onto a phosphor screen. The phosphor screen is either imaged onto the CCD or coupled with fiber-optics. Modern CCD and sCMOS imaging systems have resolutions ranging of several megapixels and bit-depths between 12 and 16, meaning that each pixel can return a value between 0 and $2^{12}(4,096)$ to $2^{16}(65,536)$.

Scientific camera assemblies are often Peltier cooled to reduce thermal noise with the intensifier and detector. Cooling is often required as thermal interactions result in a non-zero baseline reading called "dark-charge." This, along with the uniformity of the detection system (the CCD, intensifier and imaging optics), must be corrected for, particularly in quantitative measurements. Intensified scientific cameras are also prone to noise, which may be quantified using the signal-to-noise (SNR) ratio for a particular experiment or dataset. Signal may be effectively increased through the use of on-chip binning where a square number of pixels (usually four) act as a "superpixel" at a cost of 
in-plane resolution. This in-plane resolution is often less than the light sheet thickness which is typically $\sim 0.1-0.2 \mathrm{~mm}$ (Gordon et al., 2008; Medwell et al., 2008; Kaiser and Frank, 2011; Ye et al., 2016) and limits the actual resolution of the imaging system. Smoothing is a means of improving SNR in raw data prior to post-processing. Smoothing may commonly be applied as square median or Gaussian filters, however "contour-aligned smoothing," an anisotropic median filter which obtains filter sizes from a reference image, has shown significant success in improving SNR by up to a factor of ten (Starner et al., 1995).

Measurements made using pulsed lasers provide instantaneous data which may be analyzed in isolation to study transient processes such as ignition or instabilities or as part of an ensemble of repeated measurements. It is critical to ensure that a sufficient number of measurements are used in calculating mean and root-mean-squared deviation from the mean (often simply referred to as the RMS) to ensure convergence. In laminar or statistically-stationary turbulent flames, this number is not a function of the measurement rate (e.g., in $\mathrm{Hz}$ ) on the condition that measurements are not biased by individual, transient processes. For example, high-repetition rate $(\sim \mathrm{kHz})$ diagnostics may require more measurements to provide mean data, because processes such as the formation and evolution of an ignition kernel may be captured over several measurements and would not be independent from one-another. Despite this, the actual time required to record a sufficient number of independent data points to be statistically converged is still likely to be faster at $1 \mathrm{kHz}$ than at $10 \mathrm{~Hz}$.

Quantitatively, the convergence of mean data may be assessed using the standard-error-of-the-mean. It is important to highlight that this uncertainty is not the same as the RMS of the data. The standard-error-of-the-mean captures the statistical uncertainty of the mean data and is evaluated as the standard deviation of the measured data, divided by the square-root of the number of independent samples. This metric provides a range within which the mean data should lie and a range of uncertainty for comparison with modeling studies. As the standard-errorof-the-mean decreases with larger sample sizes, this statistical uncertainty may be readily reduced to within a few percent of the measured mean value using several hundred measurements.

Convergence of the RMS data requires more independent images than mean data. These RMS data represent the physical variations in the measurements, rather than the statistical uncertainty of mean data. The RMS consequently represents the statistical variation due to factors such as turbulence and may be further used to validate the choice of probabilistic distributions in numerical models.

\subsection{Quantitative Laser Diagnostics}

Laser diagnostics can provide experimental single-point (0-D), line (1-D), and image (2-D) data produced by the interaction of coherent light and the constituents of a flame. Laser light can interact with individual atoms, molecules, solid particles or liquids droplets, and the resultant signal can provide qualitative or quantitative data. Laser diagnostics techniques can be qualitative, quantitative using underlying and measurable physical properties, or semi-quantitative-requiring simplified modeling to produce absolute values. Each of these broad categories require varying complexity and produce different levels of diagnostic information. It is important, however, that they be clearly distinguished to avoid confusion to the readers of experimental studies.

Qualitative experimental measurements are the simplest form of laser-based diagnostics techniques. Measurements, such as qualitative LIF or Raman scattering, are often used to indicate the presence of certain chemical species in flames, such as the $\mathrm{OH}, \mathrm{CH}$, or NO radicals (Arndt et al., 2013; Foo et al., 2017; Macfarlane et al., 2017; Sidey and Mastorakos, 2017; Evans et al., 2019d), polycyclic aromatic hydrocarbons (PAH) species (Bartos et al., 2017; Sirignano et al., 2017; Makwana et al., 2018; Wang et al., 2018), $\mathrm{N}_{2}$ or fuel gases (Starner et al., 1995; Jiang et al., 2017). The signals emitted from LIF and Raman processes are dependent on the incident laserpulse energies, laser wavelengths, the corresponding detection wavelengths, and the proportion of light that is captured. Therefore, the intensity of the detected signal cannot be directly interpreted as estimates of absolute values. This may be due to unknown incident beam profiles, or a lack of calibration data or reference-images. Even accounting for corrections to the laser energy distribution, detector uniformity and dark-charge, the collected signals do not necessarily represent normalized species distributions. Similarly, it is often required to calculate or estimate local collisional quenching (a function of the gas composition) and/or the Boltzmann distribution of the probed species-as described below.

The discrete energy states occupied by atoms and molecules, in the absence of reactions or irradiation, are governed by the Boltzmann distribution. According to this distribution, the ratio of atoms or particles in two energy levels, separated by an energy difference $\left(\Delta E_{i j}\right)$ at some temperature $(T)$ is given by:

$$
\frac{N_{j}}{N_{i}}=e^{-\Delta E_{i j} /(k T)}
$$

where $k$ is the Boltzmann constant, $N$ the population fraction in each energy state and $j$ is the higher energy state. This relationship becomes important when selecting excitation transitions for LIF experiments, and may be used to determine temperatures from comparative measurements of atomic, such as indium (Medwell et al., 2009a) or gallium (Borggren et al., 2017), and simplemolecular species, such as NO or OH (McMillin et al., 1994; Richardson et al., 2016). Similarly, the change in temperature across the reaction zone can introduce additional uncertainties in qualitative measurements (Sidey and Mastorakos, 2015; Kruse et al., 2019), or semi-quantitative measurements which do not include corrections to temperature (Medwell et al., 2007, 2008, 2009b; Ye et al., 2018). The latter approach may be considered valid following careful selection of excitation wavelength, to ensure little variation (e.g., $\lesssim 10 \%$ Medwell et al., 2007) in the Boltzmann fraction across the reaction zone.

Collisions between molecules are fundamental to reacting flows. While many collisions may cause, or enhance, chemical reactions, collisions between vibrationally-excited species and large particles may also result in de-excitation, without the 
emission of a photon. This process is known as collisional quenching and directly affects LIF measurements. Collisional quenching of an excited species may be evaluated using the local temperature, known collisional quenching coefficients between two-given species (e.g., $\mathrm{OH}$ and $\mathrm{N}_{2}$ ) and their number densities. This dependence on number density allows the effects of collisional quenching to be estimated using only the most populous species in a flame, such as $\mathrm{O}_{2}, \mathrm{~N}_{2}, \mathrm{CO}, \mathrm{CO}_{2}$, and fuel gases. Furthermore, although these coefficients are well-known for a number of diatomic species, such as $\mathrm{OH}$ and $\mathrm{NO}$, their calculation is significantly more challenging for more complex intermediary combustion species, such as $\mathrm{CH}_{2} \mathrm{O}$, preventing their quantification.

Temperature-dependent population distributions result in temperature-dependent absorption and Raman spectra. These spectra may be theoretically computed and subsequently used to determine flame temperatures and compositions by scanning excitation wavelengths in laminar flames or, with more application to turbulent flames in hot and diluted coflows, collecting single-shot spectra at a point or line from RayleighRaman (Carter and Barlow, 1994; Masri et al., 1996; Barlow et al., 2000, 2015; Barlow, 2007; Dunn et al., 2009; Magnotti and Barlow, 2017) or CARS (van Veen and Roekaerts, 2005; Oldenhof et al., 2010; Correia Rodrigues et al., 2015a). These techniques are both capable of high accuracy temperature measurements to within 1.5\% (Magnotti and Barlow, 2017) and 2\% (Roy et al., 2010), although Rayleigh-Raman simultaneously provides quantified measurements of mixture fraction and major species to within 10\% (Magnotti and Barlow, 2017). Specifically, in turbulent flames, accuracies of $2 \%$ are possible in measurements of $\mathrm{CH} 4$ (Magnotti and Barlow, 2017), 3\% of $\mathrm{N}_{2}$ concentration, whilst $\mathrm{CO}_{2}$ and $\mathrm{H}_{2} \mathrm{O}$ concentrations can be measured to within $6 \%$ and equivalence ratio $(\Phi)$ measured to within $10 \%$ (Fuest et al., 2012). Similarly, concentrations of $\mathrm{O}_{2}$ may be measured to within $2 \%$ in laminar flames (Fuest et al., 2012). Both techniques have been extensively described in previous literature (Eckbreth, 1996; Kohse-Höinghaus and Jeffries, 2002), and are not discussed in-depth here.

Laser energy profiles in pulsed laser systems vary shot-toshot. Whilst energy-profiles can be reasonably approximated as Gaussian for qualitative measurements (Cavaliere et al., 2013), and have been assumed as constant between shots in studies of non-linear and saturated LIF (Dunn et al., 2007a), linear LIF and Rayleigh techniques-where signal is proportional to laser fluence (energy divided by beam area) - are sensitive to inhomogeneities in the energy profile, as is the singleshot NTLAF thermography technique (Medwell et al., 2009a). Calibration data or simultaneous imaging of reference burners can be used to provide ensemble-averaged or instantaneous profiles, respectively, and additionally provide values for other system-calibration constants, such as image solid-angle and collection efficiency (Medwell et al., 2007, 2009b; Dunn and Masri, 2010).

For fluorescence measurements of individual species, the collected signal is a function of both the concentration of the species and the local temperature. The measured signal depends on the number density ( $n$, see section 2.1 ) of the species of interest as each pixel or detector images a specified spatial volume, rather than a predetermined number of moles of gas. The number density for species $i$ is given by:

$$
n_{i}=X_{i} \cdot \frac{P \cdot N_{A}}{R \cdot T}
$$

where $X$ is the mole fraction of species $i, P$ is the pressure, $N_{A}$ is Avogadro's number, $R$ the universal gas constant and $T$ is the temperature. It is therefore possible to estimate mole fractions from simultaneous species and temperature measurements, however, this introduces a dependency on accurate temperature measurements. Accordingly, species measurements may be reported in units of number density (Medwell et al., 2007, 2008; Ye et al., 2018). This coupling has promoted the use of iterative solution processes for calculating the mole fraction of species such as $\mathrm{OH}$ simultaneously with temperature (Gordon et al., 2008, 2009).

\section{VELOCITY-FIELD MEASUREMENTS}

Velocity and turbulence measurements in flames stabilized in JHC burners are critical for understanding turbulence-chemistry interactions and providing accurate boundary conditions for numerical model validation. Optical velocity measurements in gaseous flames are either performed using particle image velocimetry (PIV) or laser Doppler anemometry (LDA, also known as laser Doppler velocimetry). Both of these techniques require seeded particles which are capable of enduring flame temperatures, such as alumina, and faithfully following the flow. This latter condition requires a Stokes number less than unity and typically demands micron or sub-micron diameter particles (Honoré et al., 2000; Oldenhof et al., 2010; Oldenhof et al., 2012; Barlow et al., 2012). The condition that particles be spherical is particularly critical for LDA measurements, which may also be used to measure the velocity of fuel droplets in dilute spray flames (Kawazoe et al., 1990; Yuan, 2015). The reliance on particles in these techniques makes them susceptible to thermophoresis effects, where gas expansion due to strong thermal gradients results in local pressure differential biasing the flow away from the high temperature region. This effect scales with $\Delta T$ (Mungal et al., 1995; Frank et al., 1999), and is hence less of a concern in the near-field region of jet flames in hot and diluted coflows, where peak flame temperatures and thermal gradients are reduced (Plessing et al., 1998; Dally et al., 2002; Cavaliere and de Joannon, 2004). Particle seeding must be ensured in the both the jet and hot coflow streams to ensure even and unbiased measurements in the mixing region. This requirement to seed particles into the coflow has restricted velocity measurements in JHC burners which generate hot and diluted coflows on porous bed burners (Dally et al., 2002; Medwell et al., 2007, 2008; Ye et al., 2017, 2018; Evans et al., 2019b; Kruse et al., 2019).

Particle image velocimetry is a planar technique using Mie scattering from particles illuminated by a pair of pulsed lasers separated by a known time interval. Image pairs are most often captured using two identical lasers and a doublepulsed camera, although other configurations (such as two 


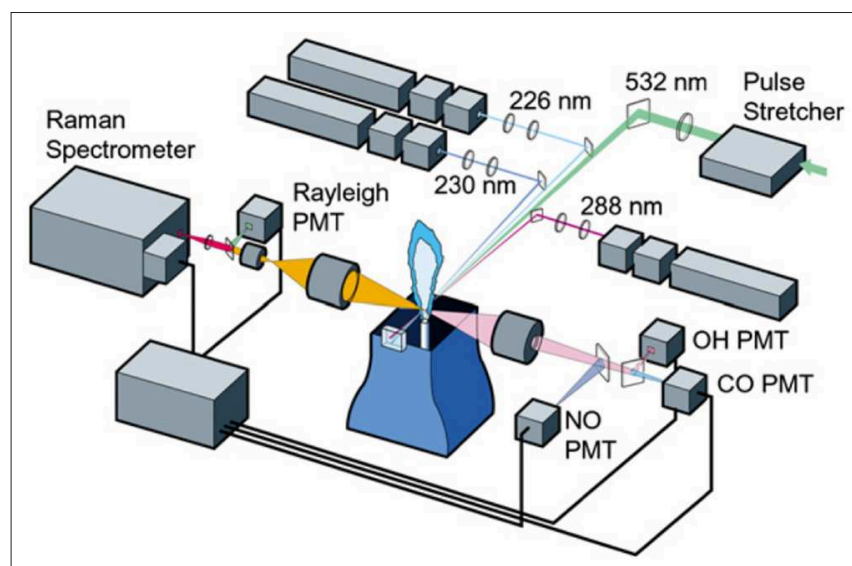

FIGURE 2 | Layout of a single-point Rayleigh-Raman-LIF experiment, including measurements of CO-, OH-, and NO-LIF (Barlow, 2007). Reprinted from Proceedings of the Combustion Institute, vol. 31, R.S. Barlow, "Laser diagnostics and their interplay with computations to understand turbulent combustion," pp. 49-75, Copyright 2007, with permission from Elsevier.

cameras or lasers of different colors) have been demonstrated. The displacement of groups of particles are subsequently calculated using cross-correlation between the image pairs, using interrogation windows of between 8 and 64 pixels. The size of interrogation windows and timing between pulses is dictated by the requirement that sufficient particles must be present in the corresponding interrogation windows in each image. As such different timings or multiple cameras may be required to measure velocities at different locations in a flame. The use of interrogation windows results in less velocity vectors than imaging pixels, although cameras used for PIV are typically of higher resolution than ICCD cameras, used for species and temperature measurements. Spurious velocity vectors may be generated by particles entering or leaving the light sheet and the need to avoid this has led to the development and refinement of stereo and tomographic PIV, employing thicker light sheets and multiple cameras. Scattering from soot and highly luminous flames may also provide interference.

Particle image velocimetry is able to provide planar information of the velocity field, and may be used to estimate the local strain-rate, vorticity and the RMS fluctuations in velocity. Velocities calculated by PIV inherently overestimate true values in regions of high gradients due to the need for interrogation windows (Kähler et al., 2012), but can be as accurate as $2 \%$ of the maximum flow speed (Kamal et al., 2015). Despite this, alternative image post-processing approaches have been proposed. When used in conjunction with scalar imaging techniques such as PLIF, PIV can provide information about fluid entrainment, local turbulence intensity and the behavior of the local flow-field during events such as ignition or extinction.

Laser Doppler anemometry measures the Doppler shift from a modulated, continuous wave laser to calculated particle velocity at a single point in a single direction. This may be extended to two or three lasers to measure multiple velocity components simultaneously. Unlike PIV, LDA is not limited by the repetition rate of a laser or camera and data are collected at sufficiently high frequencies to calculate first and second temporal derivatives at a single point. This technique is often used for measuring velocities at the jet and coflow exits in canonical burners with an accuracy within $0.5 \%$ for mean velocity and $2 \%$ for RMS (Wu et al., 2006; Kamal et al., 2015).

\section{SPECIES MEASUREMENTS}

Concentrations and images of major, intermediary and radical combustion species in jet flames in hot and diluted coflows have been obtained through single-point Rayleigh-Raman-LIF (Cabra et al., 2002, 2005; Dally et al., 2002; Dunn et al., 2009; Sepman et al., 2013) and planar LIF (Medwell et al., 2007, 2008, 2009b; Gordon et al., 2008, 2009; Dunn et al., 2009; Oldenhof et al., 2011; Oldenhof et al., 2012; O'Loughlin and Masri, 2011, 2012; Arndt et al., 2012, 2013; Sidey and Mastorakos, 2015; Ye et al., 2016, 2017, 2018; Kruse et al., 2019) measurements.

Single-point Rayleigh-Raman-LIF experiments performed in JHC burners have provided quantitative ensemble data of simultaneously measured temperature, major species and mixture fraction via Rayleigh-Raman, with CO- and OH-LIF (Cabra et al., 2002, 2005; Dally et al., 2002; Dunn et al., 2009; Sepman et al., 2013), often using an experimental configuration similar to that shown in Figure 2. The configuration in Figure 2 shows a $532 \mathrm{~nm}$ beam for Rayleigh-Raman measurements and three UV beams for CO-, OH- and NO-LIF, as well as lenses and photomultiplier tubes (PMTs) for signal detection. These experiments have investigated ignition processes and finite-rate chemistry in premixed (Dunn et al., 2009) and non-premixed flames in hot and diluted coflows (Dally et al., 2002; Sepman et al., 2013), including partial-premixing leading to autoignition (Cabra et al., 2002, 2005) and the structure of flames stabilized in hot coflows with as little as $3 \% \mathrm{O}_{2}$. These high fidelity measurements have provided mean and RMS data, across a range of discrete radial and axial locations, which may be represented in scatter-plots, such as those presented in Figure 3 for an autoignitive, lifted $\mathrm{CH}_{4}$ /air flame (Cabra et al., 2005). The data produced by these studies may be compared against strained opposed-flow or equilibrium chemistry, as done in Figure 3, or directly used for validation of combustion models within computational fluid dynamics frameworks (Hochgreb, 2019). The comparisons of scatter data against laminar opposed-flow simulations allow for the identification of regions where the timeaveraged flames may or may not be treated as steady, laminar flamelets (Sepman et al., 2013). It is important to note from Figure 3 that the majority of measured points in diluted $\mathrm{H}_{2}$ flames lie on either the pure mixing or strained-flamelet lines after the $z / d_{\text {jet }}$ of 11 , with the remainder of points indicating transient ignition processes (Cabra et al., 2005). Here $z$ is the downstream location and $d_{j e t}$ is the inner diameter of the pipe from which the central fuel jet issues. These transient processes were less prevalent for $\mathrm{CH}_{4}$ /air in a hotter coflow with less $\mathrm{O}_{2}$, with the flame transitioning from almost pure mixing to completely burnt between $40 \lesssim z / d_{\text {jet }} \lesssim 50$ (Cabra et al., 2005). Similarly, mean temperature and species measurements in a JHC burner with both preheated fuel and a hot coflow with $\sim 4 \% \mathrm{O}_{2}$ 


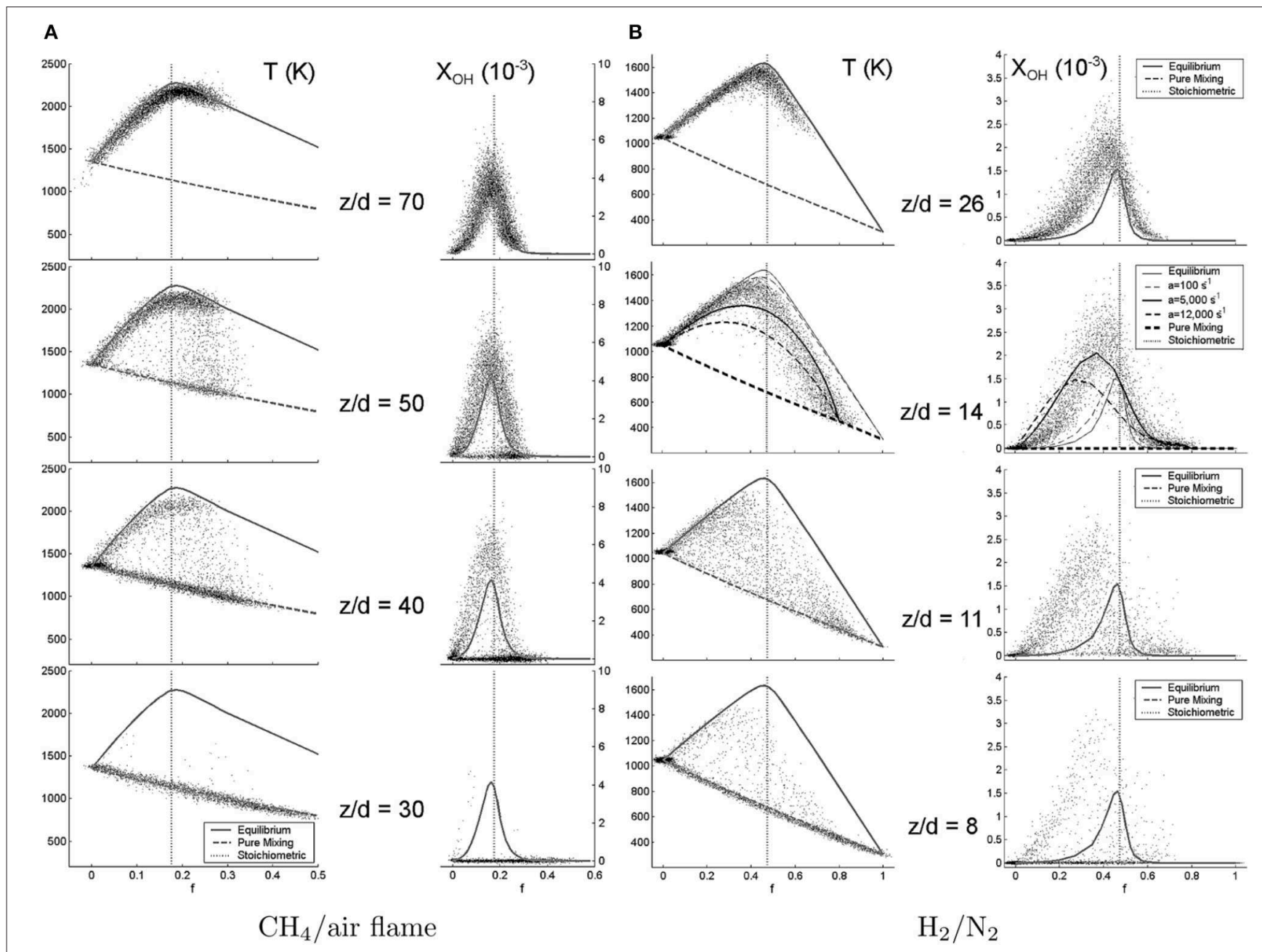

FIGURE 3 | Scatter-plot of instantaneous temperature and $\mathrm{OH}$ mole fraction at four axial stations in two different flames [with (A) $\mathrm{CH}_{4} /$ air and (B) $\mathrm{H}_{2} / \mathrm{N}_{2}$ fuels] measured using Rayleigh-Raman-LIF. Curves represent calculated distributions (Cabra et al., 2005). Reprinted from Combustion and Flame, vol. 143, R. Cabra, J.Y. Chen, R.W. Dibble, A.N. Karpetis, R.S. Barlow, "Lifted methane-air jet flames in a vitiated coflow," pp. 491-506, Copyright 2005, with permission from Elsevier.

in the coflow demonstrated evidence of incomplete combustion, although the results did not offer any indication of whether the flames were dominated by transient processes (e.g., $z / d_{\text {jet }}=40$ in at Figure 3) or if there was a bimodal distribution between burning and pure mixing states (Sepman et al., 2013).

Simultaneous planar LIF (PLIF) imaging provides increased spatial information about species distributions and may allow for direct, two-dimensional comparison of the spatial distributions and, in some cases, concentrations of intermediary and radical species (as well as the flow- and temperature-fields). Simultaneous planar imaging of $\mathrm{OH}$ and $\mathrm{CH}_{2} \mathrm{O}$ has been undertaken as part of numerous experimental campaigns in the JHC configurations (Medwell et al., 2007, 2008; Gordon et al., 2008, 2009; Duwig et al., 2012; Macfarlane et al., 2017, 2018; Ye et al., 2018). One such experimental configuration is represented in Figure 4, providing an overview of the optical layout required for simultaneous imaging of $\mathrm{OH}, \mathrm{CH}_{2} \mathrm{O}$ and Rayleigh scattering for temperature (discussed in more detail in section 5), presented in Figure 5. The experimental arrangement shown in Figure 4 includes two dye-lasers for PLIF imaging and a third Nd:YAG laser for Rayleigh scattering thermometry. The laser sheets are co-planar in the imaging region. Overlap is achieved through the use of long-wave-pass (LWP) dichroic mirrors (also referred to as dichroic beamsplitters) which transmit light with wavelengths greater than some design value, and reflect light with shorter wavelengths. Short-wave-pass (SWP) dichroic mirrorsnot used in the configuration shown in Figure 4-transmit shorter wavelengths and reflect longer wavelengths. Dedicated ICCD cameras are used to separately image the OH-PLIF, $\mathrm{CH}_{2} \mathrm{O}$ PLIF and Rayleigh scattering signals, normal to the laser beam path (Medwell et al., 2007, 2008).

The image "triplets" presented in Figure 5 show $\mathrm{OH}, \mathrm{CH}_{2} \mathrm{O}$ and temperature from two separate studies. The figure shows images taken from a study of turbulent $\mathrm{C}_{2} \mathrm{H}_{4}$ flames in different coflows issuing into $1100 \mathrm{~K}$ coflows with $3 \%$ and $9 \% \mathrm{O}_{2}$, by volume and ignition kernel formation for a turbulent natural 


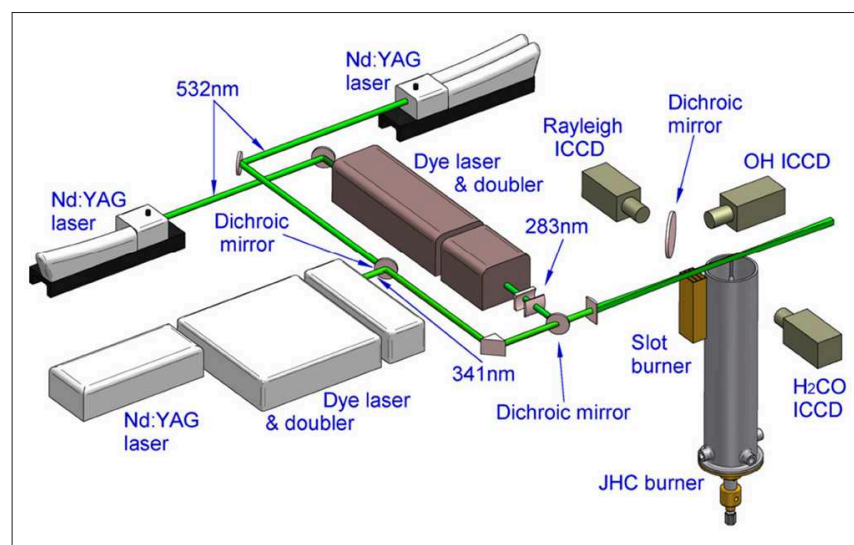

FIGURE 4 | Layout of a planar Rayleigh-LIF experiment, including measurements of $\mathrm{OH}$ - and $\mathrm{CH}_{2} \mathrm{O}$-LIF (Medwell et al., 2007). Reprinted from Combustion and Flame, vol. 148, P.R. Medwell, P.A.M. Kalt, B.B. Dally, "Simultaneous imaging of $\mathrm{OH}$, formaldehyde, and temperature of turbulent nonpremixed jet flames in a heated and diluted coflow," pp. 48-61, Copyright 2007, with permission from Elsevier.

gas (NG)/Helium ( $~ 53 \%$ He by volume) flame issuing into a $1475 \mathrm{~K}$ coflow with $11 \% \mathrm{O}_{2}$, by volume. Image triplets in Figure 5 show different flame-fronts and ignition structures. These include "weak-to-strong" transition points (Figure 5A) labeled $9 \% \mathrm{O}_{2}-\mathrm{C}_{2} \mathrm{H}_{4}, 9 \% \mathrm{O}_{2}-\mathrm{C}_{2} \mathrm{H}_{4} /$ Air and $9 \% \mathrm{O}_{2}-\mathrm{C}_{2} \mathrm{H}_{4} / \mathrm{N}_{2}$ which are further discussed in section 7), as well as lifted tripleflames and ignition kernels (Figure 5B). It should be noted, that although a fluorescence signal may appear to be present on the centerline in the measured $\mathrm{OH}$-LIF profiles of the $\mathrm{C}_{2} \mathrm{H}_{4}$ flames in Medwell et al. (2008) (not reproduced here), this is due to Raman scattering from the fuel and is not indicative of $\mathrm{OH}$.

Imaging of $\mathrm{CH}_{2} \mathrm{O}$ is most commonly performed using the Nd:YAG third-harmonic wavelength of $355 \mathrm{~nm}$ (Gordon et al., 2007, 2008; Duwig et al., 2012; Macfarlane et al., 2017, 2018; Ye et al., 2018) or-less often-near $341 \mathrm{~nm}$ using a frequencydoubled tunable-dye laser (Medwell et al., 2007, 2008). The latter approach targets a specific energy transition, which allows for amelioration of the effect of Boltzmann fraction on the $\mathrm{CH}_{2} \mathrm{O}$ signal (Medwell et al., 2007). Significant work has been undertaken to estimate Boltzmann corrections for excitation by $355 \mathrm{~nm}$ photons (Gordon et al., 2008; Macfarlane et al., 2018). The increased number of assumptions in using $355 \mathrm{~nm}$ for excitation is, practically, outweighed by the experimental simplicity of using a frequency-tripled Nd:YAG laser with 30-300 mJ/pulse (Macfarlane et al., 2018; Ye et al., 2018) compared to a frequency-doubled tunable-dye laser outputting $\sim 10 \mathrm{~mJ} /$ pulse (Medwell et al., 2007, 2008). In addition to this, temperature-dependent quenching corrections have been estimated for $355 \mathrm{~nm} \mathrm{CH} \mathrm{CH}_{2} \mathrm{O}$-[P]LIF based on calibration (Paul and Najm, 1998; Kyritsis et al., 2004; Gordon et al., 2008) or estimated $\mathrm{O}_{2}$ and $\mathrm{N}_{2}$ concentrations (Yamasaki and Tezaki, 2005; Macfarlane et al., 2018) with temperatures dependencies between $T^{-1}-T^{-0.5}$. The choice of temperature exponent is most significant in the preheat zone, and has little effect on the estimated normalized concentrations in the reaction zone, near the peak LIF signals (Kyritsis et al., 2004; Gabet and Sutton, 2014).
Despite this, calculations of constant quenching cross-sections have shown only minor differences from a $T^{-0.5}$ dependence model in premixed flames (Ayoola et al., 2006).

\section{THERMOGRAPHY IN GASEOUS, SOOT-FREE FLAMES}

Temperature measurements in flames in JHC burners have been undertaken using semi-quantitative Rayleigh scattering (Dunn et al., 2007a; Medwell et al., 2007, 2008; Gordon et al., 2008; Ye et al., 2018), Rayleigh-Raman (Cabra et al., 2002, 2005; Dally et al., 2002; Dunn et al., 2009), CARS (Oldenhof et al., 2010, 2011; Correia Rodrigues et al., 2015a,b), and NTLAF (Evans et al., 2019b; Kruse et al., 2019). Of these techniques, Rayleighbased techniques may only be used in gaseous, soot-and-dropletfree "clean" flames, in cases without significant background scattering: fluorescence or non-linear techniques are required in sooty or particle-or-droplet-laden flames.

The hot and diluted coflows of JHC flames suppress the formation of soot (Medwell et al., 2008; de Joannon et al., 2012; Ye et al., 2016, 2017; Evans et al., 2017b, 2019b). Soot may be suppressed for typically sooty fuels such as ethylene under MILD combustion conditions (Medwell et al., 2008; Evans et al., 2017b). In clean flames, thermometry may be performed using Rayleigh scattering. This method has been used to estimate temperaturefields in JHC-stabilized flames (Dunn et al., 2007a; Medwell et al., 2007, 2008; Gordon et al., 2008; Ye et al., 2018) by extracting number density from a location with a known effective Rayleigh cross-section $\left(\sigma_{e f f}\right)$. Local values of $\sigma_{e f f}$ are a function of the local composition, and is evaluated using the species with significant mole fractions. This includes $\mathrm{N}_{2}, \mathrm{O}_{2}, \mathrm{H}_{2}, \mathrm{H}_{2} \mathrm{O}, \mathrm{CO}_{2}, \mathrm{CO}$ and all constituents of the fuel stream (Gordon et al., 2008). The calculation of the cross section may also require intermediary species such as $\mathrm{C}_{2} \mathrm{H}_{2}$ and $\mathrm{C}_{2} \mathrm{H}_{4}$ which are formed in significant concentrations during the combustion of larger hydrocarbons (Ye et al., 2015).

The determination of temperature from Rayleigh scattering measurements depends on both the accuracy of the estimated composition and scattering cross-section. As it is not feasible to measure the concentrations of all species, the composition of the flames is estimated using opposed-flow flamelet calculations in conjunction with estimations determined from Raman scattering and/or PLIF measurements. The former approach was discussed at length in section 2.4 and may probe multiple species to provide quantitative measurements after extensive calibration, although this has currently been restricted to point and line measurements only due to the high laser energies and complex optical layouts required. Spontaneous planar Raman has, however, been performed in a non-reacting $\mathrm{H}_{2} / \mathrm{N}_{2}$ system using a $10 \mathrm{kHz}$ $532 \mathrm{~nm}$ laser delivering $750 \mathrm{~mJ}$ over a pulse duration of $70 \mathrm{~ns}$ at pressures ranging between atmospheric and 20 bar (Jiang et al., 2017).

Species estimates for Rayleigh thermometry may be calculated using opposed-flow flame calculations. This approach requires knowledge of the reaction zone and hence must include a simultaneous measurement of a reaction-zone-indicator, such as $\mathrm{OH}$ or $\mathrm{CH}$. This approach is valid for line or planar images, where 
A

(a) $3 \% \mathrm{O}_{2}-\mathrm{C}_{2} \mathrm{H}_{4}$

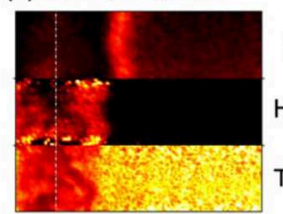

(c) $3 \% \mathrm{O}_{2}-\mathrm{C}_{2} \mathrm{H}_{4} / \mathrm{H}_{2}$

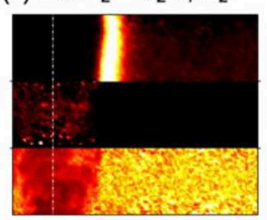

(e) $3 \% \mathrm{O}_{2}-\mathrm{C}_{2} \mathrm{H}_{4} /$ Air

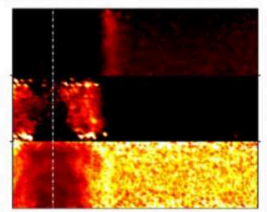

(g) $3 \% \mathrm{O}_{2}-\mathrm{C}_{2} \mathrm{H}_{4} / \mathrm{N}_{2}$
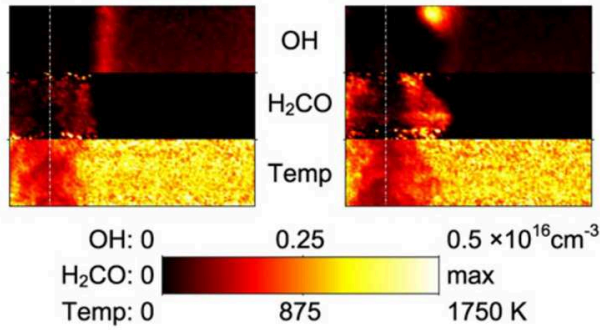

$\mathrm{C}_{2} \mathrm{H}_{4}$-based flames

(b) $9 \% \mathrm{O}_{2}-\mathrm{C}_{2} \mathrm{H}_{4}$ $\mathrm{OH}$

$\mathrm{H}_{2} \mathrm{CO}$ Temp

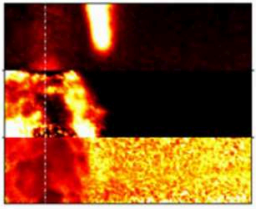

(d) $9 \% \mathrm{O}_{2}-\mathrm{C}_{2} \mathrm{H}_{4} / \mathrm{H}_{2}$

$\mathrm{OH}$

$\mathrm{H}_{2} \mathrm{CO}$

Temp

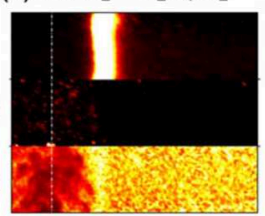

(f) $9 \% \mathrm{O}_{2}-\mathrm{C}_{2} \mathrm{H}_{4} /$ Air

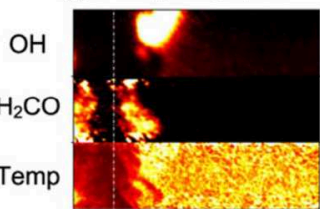

(h) $9 \% \mathrm{O}_{2}-\mathrm{C}_{2} \mathrm{H}_{4} / \mathrm{N}_{2}$

$\mathrm{OH}$

$\mathrm{H}_{2} \mathrm{CO}$

Temp

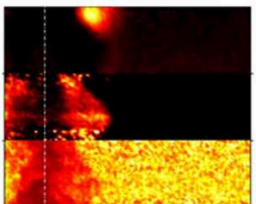

$\max$

B

(n)

FIGURE 5 I Sets of $\mathrm{OH}, \mathrm{CH}_{2} \mathrm{O}$ and temperature image "triplets" of $\mathrm{C}_{2} \mathrm{H}_{4}$-based (Medwell et al., 200 on a Jet in Hot Coflow (JHC) burner," pp. 100-113, Copyright 2008, with permission from Elsevier. Right (B): reprinted from Combustion and Flame, vol. 155, R.L. Gordon, A.R. Masri, E. Mastorakos, "Simultaneous Rayleigh temperature, $\mathrm{OH}$ - and $\mathrm{CH}_{2} \mathrm{O}-\mathrm{LIF}$ imaging of methane jets in a vitiated coflow," pp. 181-195, Copyright 2008, with permission from Elsevier.

only one reaction zone is evident. Instances with "branched" reaction zones prohibit the assignment of "fuel" and "oxidant" sides of the reaction zone, and the validity of the opposed-flow flame approximation. The reacting or mixing-only opposed-flow calculations, allow for row-by-row matching of the calculated $\sigma_{\text {eff }}$ from which an absolute temperature may be calculated. Typical uncertainties in this technique are approximately $10 \%$, predominantly due to uncertainties in $\sigma_{\text {eff }}$ and calibration assumptions (Gordon et al., 2008).

Rayleigh scattering may be performed using precalibrated beam profiles or a reference burner. The latter serves as a beam profile, species and temperature reference, which also lends itself to semi-quantified species measurements. Furthermore, polarization filters may be incorporated into the imaging system to reduce the influence of background scatter. The use of polarization filters, however, necessitates an additional term in the scattering equation to account for depolarization along the line-of-sight between the burner. This term is called the "King correction factor" and is a result of depolarization due to non-spherical molecules. This may affect the resulting measurements by up to 5\% (Dunn et al., 2009). Depolarization may also be leveraged for species measurement, however, by measuring both the polarized and depolarized components of the Rayleigh signal and has been successfully demonstrated in simple jet flames (Fielding et al., 2002; Frank et al., 2002; Schieß1 et al., 2009). The depolarized signal is approximately two orders of magnitude weaker than the polarized signal, although still an order of magnitude greater than spontaneous Raman scattering (Fielding et al., 2002). Although the effective signal-to-noise ratio (SNR) could further be reduced through the application of contour-aligned smoothing (Starner et al., 1995). The ratio of the two signals, with a priori knowledge of the depolarization of each species, subsequently allows for the estimation of the local mixture and, hence, temperature (Fielding et al., 2002; Frank et al., 2002; Schießl et al., 2009).

Simultaneous measurements of species and temperature may be performed in "clean" flames using the previously described Rayleigh-Raman technique. Although this is a very 
well established technique (Masri et al., 1996; Nguyen et al., 1996; Frank and Barlow, 1998; Cabra et al., 2002; Dally et al., 2002; Barlow et al., 2005, 2015; Dunn et al., 2010; Magnotti and Barlow, 2017), it suffers from the low signal provided by spontaneous Raman scattering, which is $\sim 1,000$ times less than the corresponding, linear Rayleigh signal (Eckbreth, 1996; Frank et al., 2002). This promotes the use of high energy lasers, although short, high power laser pulses may result in "optical breakdown" (plasma formation). This is often overcome using a combination of multiple lasers (Dunn, 2008), laser pulsestretching, combining beam-splitters and optical delay lines to extend the effective duration of a single laser pulse by up to an order of magnitude (Dunn, 2008). This is common practice to reduce the SNR of the Raman measurements, and a similar intracavity optical layout has previously been successfully demonstrated in simple jet and bluff-body flames (Starner et al., 1995; Kelman et al., 1998; Masri et al., 1998). In addition to pulse stretching, contour-aligned smoothing has been used to improve SNR of planar measurements by an order of magnitude (Starner et al., 1995). Improved SNR in point measurements has also been demonstrated by using a $\sim 10 \mathrm{~mJ} /$ pulse, $350 \mathrm{~ns}$ pulse, $527 \mathrm{~nm}$ laser in preference to a $\sim 50 \mathrm{~mJ} /$ pulse, $10 \mathrm{~ns}$ pulse, $532 \mathrm{~nm}$ laser (Mokhov et al., 2005). Notably, this shorter wavelength serves to increase the Raman scattering signal (which approximately goes as $\lambda^{-4}$, Masri et al., 1996), although UV wavelengths may increase interference due to resulting LIF signals from species such as $\mathrm{CH}_{2} \mathrm{O}$ and $\mathrm{PAH}$ (Masri et al., 1996).

The instantaneous mixture fraction field provided by line and planar imaging of species may be spatially differentiated to provide estimates of scalar dissipation. Mixture fraction can be calculated directly in Rayleigh-Raman measurements, with the assumption that the measured major species are the major contributors the mixture fraction. Mixture fraction has also been parameterized using relative Raman and Rayleigh stokes signals directly, which also maps to temperature through a one-step chemical reaction (Starner et al., 1995). Irrespective of whether they use measured or predicted species concentrations, these evaluations of mixture fraction, however, all employ a simple two-stream formula for mixture fraction used in studies of $\mathrm{CH}_{4}$ and $\mathrm{H}_{2}$ flames with air as the only oxidant stream (Bilger et al., 1990). This does not, in general, hold in regions downstream of a JHC burner where an arbitrary fuel, hot coflow and surrounding air mix. The JHC configuration therefore requires a three-stream mixture fraction to characterize the whole flow-field (Ihme and See, 2011; Ihme et al., 2012; Evans et al., 2019c).

\section{THERMOGRAPHY IN SOOTING AND SPRAY FLAMES}

Fuel particles, droplets and soot restrict the use of spontaneous scattering thermography techniques in flames. Diagnostics for particle or droplet laden flames are therefore required to investigate the behavior of complex fuels in JHC burners. Similarly, although the coflow in JHC burners suppresses soot formation, soot has still been observed in flames fuelled by aromatic hydrocarbons such as toluene (Evans et al., 2019b;
Kruse et al., 2019). The techniques which can be applied in sooting and particle or droplet laden flames may also be applicable to flames in confined chambers, although this is still restricted by optical access and the validity of underlying assumptions in the technique.

Coherent anti-Stokes Raman spectroscopy (CARS) is a nonlinear thermometry technique whereby the spectrum of a given species in the flame (often $\mathrm{N}_{2}$ ) is measured. This three-photon technique requires two crossed lasers to excite a molecule to a "virtual" energy level, with a fourth photon emitted in a predetermined direction and measured by a spectrometer (Eckbreth, 1996; Barlow, 2007). Extending this, the use of a broad linewidth "probe beam" allows for a significant portion of the emission spectrum to be measured in a single pulse. The efficacy and accuracy of this technique has been the subject of numerous reviews (Eckbreth, 1996; Kohse-Höinghaus and Jeffries, 2002; Roy et al., 2010) and, as such, the theory is not addressed indepth here. Temperatures measured with this technique can be accurate to within $2 \%$ following the appropriate selection of pump and probe wavelengths (van Veen and Roekaerts, 2005), although may be biased in regions of high thermal gradients in systems with large measurement volumes (Roy et al., 2010). This spatial limitation may be overcome using one-dimensional line measurements achievable with lasers capable of producing broad-linewidth pulses in femtosecond-scale pulses (Roy et al., 2010).

Coherent anti-Stokes Raman spectroscopy has been used in both gaseous and droplet-laden flames stabilized in JHC burners (Oldenhof et al., 2010, 2011; Correia Rodrigues et al., 2015a,b). This diagnostic has provided instantaneous, pointwise measurements of temperature to better understand flame structure and to provide accurate validation data and boundary conditions for numerical studies. Despite the high accuracy and robustness of CARS, it is widely limited to single-point measurements, although line and planar measurements have been demonstrated (Roy et al., 2010; Bohlin and Kliewer, 2014).

Two-color laser-imaging techniques may be used to provide planar imaging of flame reaction-zones. Such techniques use the Boltzmann distribution to calculate temperature from signals of the same species excited using different wavelengths. Wellcharacterized species such as $\mathrm{OH}$ may be used for two-color LIF by exciting two known energy transitions. This may be used to measure temperatures with an accuracy of $15 \%$ for mean measurements, or $30 \%$ for single-shot (Palmer and Hanson, 1996; Richardson et al., 2016), although local accuracies of 4-7\% are possible (Giezendanner-Thoben et al., 2005). Measurements are often made in the linear regime and, like other two-color techniques, inherently include the assumption that quenching is not energy level dependent. This technique is only effective, however, in regions where these species are generated and are consequently limited to the reaction unless seeded into the flame.

An alternative to probing flame radical species is to seed selected atomic species into the flame. Useful species must have appropriate energy level distributions which allow for thermal excitation of the species in flame temperatures. One such species is indium, which has an excited energy level $0.24 \mathrm{eV}$ above its ground level (Medwell et al., 2009a; Borggren et al., 2017). 
This corresponds to approximately $3 \%$ of the population existing in the excited level at a temperature of $800 \mathrm{~K}$, making it an appropriate element for temperature measurement. Indium at concentrations $\sim 100$ ppm may be introduced by several means: as sublimated $\operatorname{In}\left(\mathrm{CH}_{3}\right)_{3}$ vapor (Borggren et al., 2017), dissolved in water or ethanol as $\mathrm{InCl}_{3}$ (Medwell et al., 2009a, 2014; Chan et al., 2010; Evans et al., 2019d), or introduced directly into the gas-phase as nanoparticles through ablation (Chan et al., 2012; Medwell et al., 2012; Gu et al., 2015). All three seeding methods, however, require atomic indium to be liberated from salt or nanoparticles for TLAF measurements.

Indium TLAF measurements are performed using two-line atomic fluorescence (TLAF) by optically pumping to an excited state and measuring the emitted photons. Using the diagram in Figure 1, this technique uses two lasers corresponding to the atomic transitions $0 \rightarrow 2$ and $1 \rightarrow 2$ in indium (Medwell et al., 2009a, 2010; Chan et al., 2010; Borggren et al., 2017) and hence have been termed as the "Stokes" and "anti-Stokes" processes (Medwell et al., 2009a). Although photons may be measured at the same wavelength as the excitation wavelength, this results in interference from Rayleigh and Mie scattering. Subsequently, the signal from exciting the ground energy level (Stokes, $0 \rightarrow 2$ ) is measured at the photons corresponding to the transition to the thermally excited state $(2 \rightarrow 1)$ and probing the thermally excited state (anti-Stokes, $1 \rightarrow 2$ ) is measured using the transition to the ground state $(2 \rightarrow 0)$. This technique only provides weak signal in the linear regime and is often extended to the non-linear regime for single-shot imaging.

Non-linear excitation regime two-line atomic fluorescence (NTLAF) thermography extends TLAF from a ratio technique, providing higher measurable signal at the cost of increased complexity. A typical NTLAF arrangement is shown in Figure 6, also showing simultaneous time-resolved laser-induced incandescence (TiRe-LII) and OH-PLIF (Kruse et al., 2019). This arrangement shows the two dye lasers and three cameras required to perform NTLAF measurements, and the system required to produce conditional distributions of temperature, OH-LIF signal, soot volume fraction and soot primary particle diameter and has been applied to laminar and turbulent jet flames, as well as flames stabilized in a JHC burner (Foo et al., 2017, 2018, 2019; Gu et al., 2017; Evans et al., 2019b; Kruse et al., 2019). Specifically, simultaneous measurements of sooting toluene and toluene/nheptane flames in a JHC burner have shown both the formation of soot in the hot-coflow-controlled region (Evans et al., 2019b; Kruse et al., 2019) and the strong influence of the coflow $\mathrm{O}_{2}$ concentration on the evolution of soot, and associated radiative heat release, downstream (Evans et al., 2019b).

The NTLAF equation and its derivation were provided by Medwell et al. (2009a). It is important to note that this technique requires the calibration of three constants and that spectral overlap is ensured by using relatively broad laser linewidths $\sim 0.5 \mathrm{~cm}^{-1}$. The NTLAF technique has been shown to provide temperatures with an accuracy within 100-150 K ( 5-10\% of mean values); however, are only valid where sufficient signal exists. This conditioning roughly corresponds to flame temperatures greater than $800 \mathrm{~K}$ (due to the small population of thermally excited indium below this temperature) and $\Phi \geq 0.8$

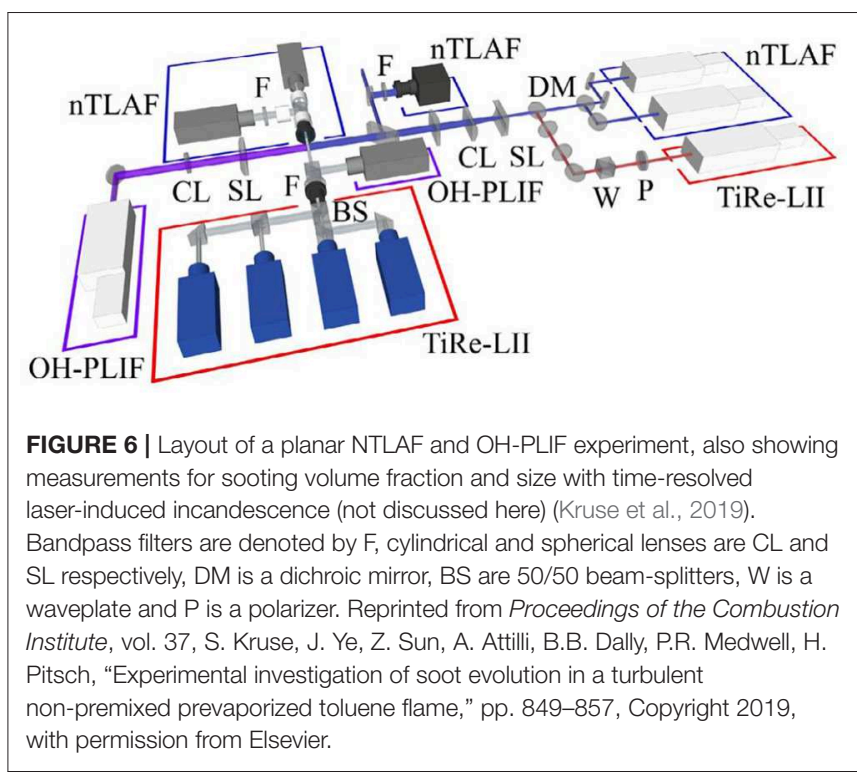

(below which the atomic indium is oxidized). Planar NTLAF thermography has been demonstrated in sooting and spray flames, although cannot capture the lean ignition processes which occur in flames in hot coflows (Cabra et al., 2005; Evans et al., 2016a). A further complication of the NTLAF technique is the large non-linear excitation regime between linear and saturated TLAF, which imposes the requirement of shot-to-shot measurements of laser energy profiles.

\section{CONTRIBUTION OF LASER DIAGNOSTICS TOWARD UNDERSTANDING FLAMES IN JHC BURNERS}

\subsection{Measurements of Temperature and Species}

Qualitative and quantitative PLIF has been used to measure and visualize structures, species distributions and infer relative magnitudes of selected reaction rates in flames stabilized in JHC burners. Comparisons between single-point measurements and equilibrium calculations (recall Figure 3) provide indications of the flame progress at different downstream locations (Dally et al., 2002; Cabra et al., 2005). With the addition of simultaneous multi-species (and hence mixture fraction) point data provided by Rayleigh-Raman measurements, LIF of radical species has been used to identify ignition at most-reactive mixture fractions and flame evolution in mixture fraction-space (Cabra et al., 2005; Mastorakos, 2009). This can be seen in the experimental data shown in Figure 3, where elevated temperatures and non-zero $\mathrm{OH}$ concentrations begin to appear in the leanest mixtures before extending to richer regions of the flame (Cabra et al., 2005). This conclusion has been further supported by direct numerical simulations (DNS) and transient flamelet modeling (Mastorakos, 2009). This technique has not, however, been performed under 
MILD combustion conditions in flames which appear visibly lifted or exhibit a "weak-to-strong transition" in a continuous flame-front (Medwell et al., 2008, 2016; Medwell and Dally, 2012a; Evans et al., 2016b; Ye et al., 2017).

The Rayleigh-Raman diagnostic technique has been extended to one-dimensional data measurements, and extensive measurements of piloted jet flames have been performed to quantify scalar dissipation, length scales and flame-sheet orientation (Karpetis and Barlow, 2002; Barlow et al., 2005; Magnotti and Barlow, 2017), these have not been performed on flames in hot and diluted coflows. This is despite strong coupling between the burning state and heat release profiles of such flames to scalar dissipation rate (Oberlack et al., 2000; Özdemir and Peters, 2001; Ihme et al., 2012; Evans et al., 2016b; Ye et al., 2016, 2017).

Planar imaging of radical species and intermediary species provides instantaneous of images in, and near, the flame-front. The imaging of specific species in the flame can be used as a surrogate for the reaction-zone, such as $\mathrm{OH}$ or $\mathrm{CH}$, or to identify fuel decomposition using species such as $\mathrm{CH}_{2} \mathrm{O}$. Aromatic hydrocarbons, such as toluene or polycyclic aromatic hydrocarbons (PAH) may also be targeted in PLIF studies as soot precursors (Sirignano et al., 2017), but often provide interference due to their broad, molecular-size-dependent absorption and emission spectra (Sirignano et al., 2017). This interference is particularly evident with high pulse powers $(\sim 10 \mathrm{~mJ} /$ pulse over $\sim 10 \mathrm{~ns}$ ), such as $355 \mathrm{~nm}$ beams used for imaging $\mathrm{CH}_{2} \mathrm{O}$ (Gordon et al., 2009; Ye et al., 2018). Despite this, $\mathrm{PAH}$ - and consequently soot-formation is suppressed with hot and diluted oxidants, reducing the potential for interference (Medwell et al., 2008; de Joannon et al., 2012; Evans et al., 2017b; Ye et al., 2017). Interference from Raman scattering can also be evident depending on the combination of LIF species and fuel-structure, and was used to explain the on-axis signal in $\mathrm{OH}$-PLIF measurements of $\mathrm{C}_{2} \mathrm{H}_{4}$ flames in a JHC burner (Medwell et al., 2008).

\subsection{Reaction-Zone Imaging in Understanding Flame Stabilization}

Images of the $\mathrm{OH}$ radical may be interpreted as representing the lean side of the reaction-zone. Consequently, OH-PLIF can provide indications of flame stabilization mechanisms, such as the formation and growth of isolated ignition kernels (Gordon et al., 2008; Oldenhof et al., 2011), triple flame bases (Gordon et al., 2008) or a "weak-to-strong transition" in a continuous flame-front (Medwell et al., 2008, 2016; Medwell and Dally, 2012a; Evans et al., 2016b; Ye et al., 2017), which may each be seen in Figure 5. The occurrence of these structures is largely dependent on the combination of fuel/oxidant composition and temperatures (Medwell et al., 2008, 2016; Medwell and Dally, 2012a; Evans et al., 2016a,b), which dictates both the stoichiometric and most-reactive mixture fractions, and the underlying flow-field, which governs the local strain-field between the fuel and oxidant streams (Ye et al., 2016). Of these mechanisms, ignition kernel formation and autoignitive triple flames have been examined at significant length, and a full discussion is not provided here (Gordon et al., 2008; Mastorakos, 2009; Yoo et al., 2011; Arndt et al., 2012, 2019; Sidey and Mastorakos, 2015; Macfarlane et al., 2017, 2018, 2019; Ramachandran et al., 2019). Observations from OH-PLIF (Medwell et al., 2008), and resulting numerical studies (Medwell et al., 2009b; Evans et al., 2016b, 2017a,b) suggest that the least studied of these mechanisms-the "weak-to-strong transition"anchors as a weakly reacting diffusion flame close to the jet exit, in $\Phi \approx 0.2$ (Evans et al., 2016a) under temperature and flowfield conditions almost identical to the laminar coflow stream. These weak diffusion flames allow for the diffusion of $\mathrm{O}_{2}$ in the fuel stream (in a process which has been termed, "reactionzone weakening" Medwell et al., 2009b) and provide enhanced formation of precursors, such as $\mathrm{CH}_{2} \mathrm{O}$ (Medwell et al., 2009b; Medwell and Dally, 2012b), before a critical "transition point" where thermal run-away occurs (Medwell et al., 2008; Evans et al., 2016b). It has been hypothesized that these weak reaction zones are confined between the extinction strain-rate on the fuelside, and the lean flammability-limit on the oxidant-side (Evans et al., 2016b). This hypothesis has been supported by Reynoldsaveraged Navier-Stokes (RANS) modeling (Evans et al., 2017a), although there has not been any experimental confirmation of this through quantitative mixture fraction measurements.

It has been shown that flame stabilization under MILD combustion conditions is highly sensitive to the radical pool in the hot oxidant stream (Medwell et al., 2013, 2016; Evans et al., 2017b; Doan and Swaminathan, 2019). These radical and intermediary species significantly reduce ignition delay times in low oxygen conditions (Medwell et al., 2013, 2016; Evans et al., 2017b; Doan and Swaminathan, 2019), but have less of an effect in conventional autoignition processes with $\gtrsim 6 \% \mathrm{O}_{2}$ (by vol.) (Medwell et al., 2016; Evans et al., 2017b). Measurable radical species such as $\mathrm{OH}$ have been reported in hot coflows with $\lesssim 9 \% \mathrm{O}_{2}$, with concentrations of equilibrium $\mathrm{OH}$ in the coflow increasing with dilution level (Medwell et al., 2007, 2008). Coflow $\mathrm{OH}$ concentrations may, however, be up to an order of magnitude less than $\mathrm{OH}$ in the flame reaction zone, particularly with the addition of $\mathrm{H}_{2}$ to the central fuel jet (Medwell et al., 2007, 2008; Evans et al., 2015b). Subsequently, coflow OH concentrations are not often visible in images used in the description of flame stabilization, such as Figure 7 (Evans et al., 2015b).

\subsection{Effects of Coflow Composition on Flame Lift-Off and Structure}

The combination of reaction-zone weakening and weak-tostrong transition points results in the appearance of a nonmonotonic trend in lift-off height with changing oxidant dilution (Medwell and Dally, 2012a), as shown in Figure 7. This figure shows an ensemble of OH-PLIF images from $\mathrm{C}_{2} \mathrm{H}_{4}$ flames issuing into $1250-\mathrm{K}$ coflows with $\mathrm{O}_{2}$ concentrations of $3-11 \%$ (by volume) (Evans et al., 2015b). The scale is kept constant in all images and the figures are normalized by the instantaneous beam-profile (Evans et al., 2015b). The figure shows that the transition/lift-off height decreases with increasing coflow $\mathrm{O}_{2}$ concentrations between 6-11\% (Figures 7J,O,P), although a distinguishable $\mathrm{OH}$ front exists in the coflow with $3 \% \mathrm{O}_{2}$ 


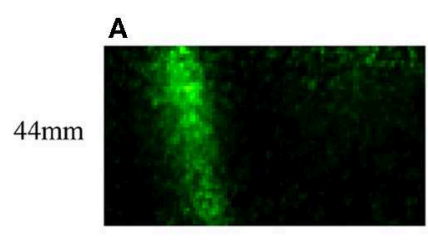

E

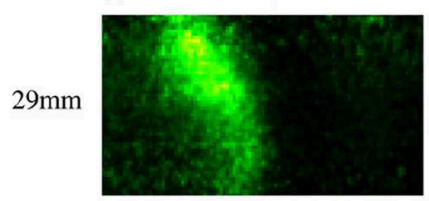

I

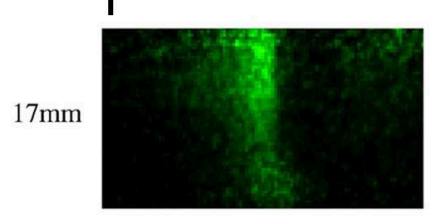

M

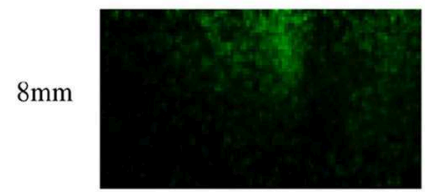

$3 \% \mathrm{O}_{2}$

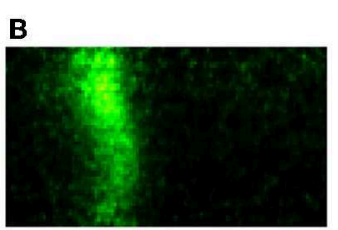

c

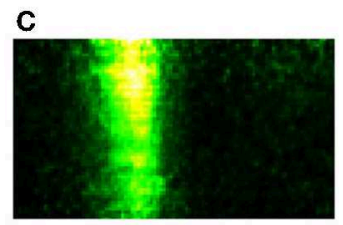

G

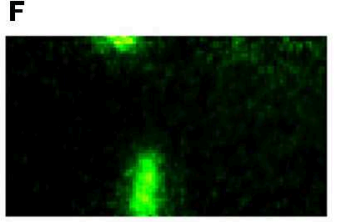

J

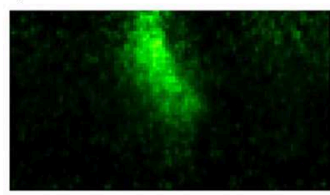

N

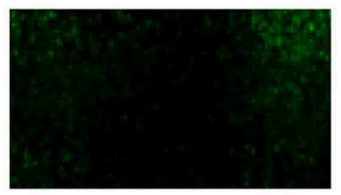

$6 \% \mathrm{O}_{2}$

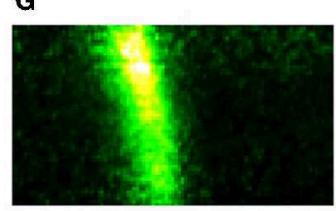

K

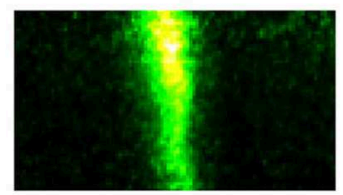

0

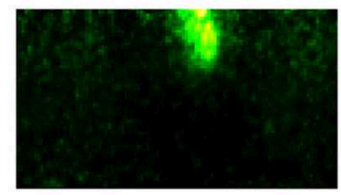

$9 \% \mathrm{O}_{2}$

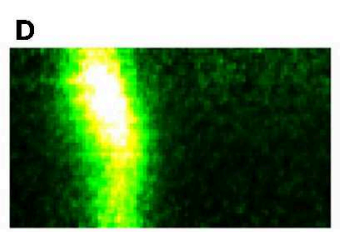

H

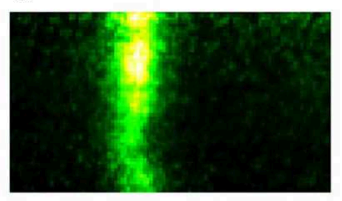

L

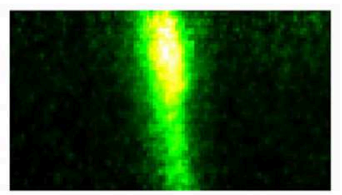

P

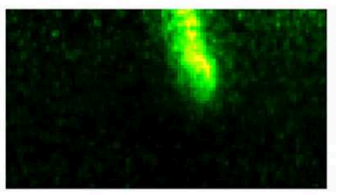

$11 \% \mathrm{O}_{2}$

FIGURE 7 | Instantaneous OH-PLIF images of ethylene jet flames centered at different heights above the jet exit plane in $1250 \mathrm{~K}$ coflows with different $\mathrm{O}_{2}$ concentrations (given in \% volume) and labeled (A-P) for discussion. The right-hand edges of the images correspond to the fuel jet centerline (Evans et al., $2015 \mathrm{~b})$.

(Figure $7 \mathbf{M}$ ) at a similar height to that in the $9 \% \mathrm{O}_{2}$ coflow. An absence of isolated ignition kernels was reported in this study (Evans et al., 2015b). These observations are consistent with similar studies of $\mathrm{C}_{2} \mathrm{H}_{4}$ (Medwell et al., 2008) and $n$-heptane (Ye et al., 2017) in JHC burners. This unbroken weak-to-strong transition is, however, in contrast to the isolated autoignition kernels seen in experimental investigations of $\mathrm{CH}_{4} / \mathrm{NG}$ (Gordon et al., 2008, 2009; Oldenhof et al., 2010, 2011) and $\mathrm{C}_{2} \mathrm{H}_{4}$ (Yoo et al., 2011; Luo et al., 2012) flames in hotter coflows (1395$1550 \mathrm{~K}$ ) with $7.6-23 \% \mathrm{O}_{2}$ (by mass). It is important to note that kernel formation in cases with less than $14 \% \mathrm{O}_{2}$ (by volume) initializes $60-80 \mathrm{~mm}$ above the jet exit plane (Oldenhof et al., $2010,2011)$ and may be subject to entrainment of quiescent air (Evans et al., 2019b). Despite this potential influence of the surrounding air, this phenomenon has also been observed in subsequent chemiluminescence imaging of $\mathrm{CH}_{4}$ flames in confined coflows with $6.9 \% \mathrm{O}_{2}$ (by volume) and coflows of 1170 1475 K (Ramachandran et al., 2019), where ignition kernels were more significantly prevalent for fuel jets with $\mathrm{Re}<10 \mathrm{k}$, than for faster jets. The burner used in this study, however, used a thickwalled central jet with an I.D. of $5.3 \mathrm{~mm}$ and O.D. of $9.5 \mathrm{~mm}$ (Ramachandran et al., 2019), which is significantly greater than the $0.2 \mathrm{~mm}$ (Oldenhof et al., 2011), $0.6 \mathrm{~mm}$ (Evans et al., 2019b; Kruse et al., 2019) or $0.9 \mathrm{~mm}$ (Cabra et al., 2002, 2005; Medwell et al., 2007, 2008, 2009b; Evans et al., 2015b; Ye et al., 2017) used in other experimental studies or continuous boundary conditions used in DNS investigations (Yoo et al., 2011; Luo et al., 2012). The differences between the observed stabilization mechanisms of jet flames with similar Reynolds number, in coflows with similar temperature and oxygen concentration but significantly different jet wall thickness (Medwell and Dally, 2012a; Ramachandran et al., 2019) demonstrates the influence of the flow-field on flame stabilization mechanisms, and differences which must be considered before directly comparing results.

Planar images of the $\mathrm{OH}$ radical in flames stabilized in hot coflows can be used to provide insight into the flame-front (Medwell et al., 2007, 2008; Gordon et al., 2008, 2009; Ye et al., 2016, 2017, 2018; Macfarlane et al., 2017, 2018, 2019) and, in combination with simultaneous PIV, its interaction with the underlying flow-field (Lyons et al., 2005; Oldenhof et al., 2011; Oldenhof et al., 2012). This latter approach is not available simultaneously with Rayleigh scattering measurements of temperature, due to the overwhelming Mie scattering signal from PIV seed particles. Images of OH-PLIF indicate the continuity of the flame-front, and may be used to identify "holes" or "ruptures" in the flame (Lyons et al., 2005). An example of this may be seen in Figure 7F. It was reported that only this case at this height exhibited any "holes" and that discontinuities were present in 35\% of images (Evans et al., 2015b). No discontinuities were observed in the other cases at any of the 
different measurement heights (Evans et al., 2015b). Although these holes may be indicative of local extinction, such features must be interpreted with caution, as they may be indicative of several different mechanisms (Watson et al., 2000; Watson et al., 2002; Lyons et al., 2005). Further information about the local mixture fraction or flow-field would, however, be required to draw definitive conclusions.

\subsection{Further Analyses of Transitional Flames and Ignition Processes}

Flame stabilization of lifted and "transitional" turbulent flames in JHC burners has been studied experimentally using laser-based diagnostics (Medwell et al., 2007, 2008; Gordon et al., 2008; Ye et al., 2016, 2017, 2018), photographs and chemiluminescence imaging (Medwell and Dally, 2012a; Evans et al., 2016b, 2017b; Ramachandran et al., 2019), analytical analyses (Evans et al., 2016b), and numerical modeling (Shabanian et al., 2013; Evans et al., 2015a, 2017a; Medwell et al., 2016). The culmination of these studies have revealed the strong influence of the oxidant radical pool (Medwell and Dally, 2012a; Evans et al., 2017b) and the effects of the underlying flow-field (Evans et al., 2016b; Ye et al., 2016) on flames in hot coflows with $\lesssim 6 \% \mathrm{O}_{2}$.

Analytical analyses of $\mathrm{CH}_{4}, \mathrm{C}_{2} \mathrm{H}_{4}$, and $\mathrm{CH}_{4} / \mathrm{H}_{2}$ diffusion flames in these coflows have suggested that MILD combustion may be reasonably approximated by a monotonic flamelet, with ignition or extinction points (Evans et al., 2016b). It is imperative to note that this analogy was proposed as a phenomenological description of the global process, rather than as a substitute for high-accuracy measurements or detailed chemical analyses (Evans et al., 2016b). The same study proposed that the weakto-strong transition may be indicative of a weak diffusion flame preceding a "conventional ignition" point (Evans et al., 2016b), as was shown in Figure 5A). Numerical modeling of transitional flames has been met with varied success (Shabanian et al., 2013; Evans et al., 2015a). Although experimentally observed weakto-strong transitions have been reproduced in RANS modeling (Evans et al., 2015a), this modeling study required significant adjustment of model parameters to replicate experimental results. This "parameter-tuning" was required due to the low turbulence Reynolds number of the jet flame (De et al., 2011; Parente et al., 2016), Damköhler number of order unity (Galletti et al., 2007; Mardani et al., 2011) and strong preferential diffusion effects (Medwell et al., 2009b). The combination of these effects has additionally, in the authors' experience, resulted in significant sensitivity to inlet conditions and subgrid models in largeeddy simulations (LES) with flamelet tabulation. Although, partially-stirred reactor and transported PDF models have demonstrated good agreement (Li et al., 2019; Wang et al., 2019a). The modeling challenges posed by this configuration highlight the need for more experimental insight and validation data for the generation of comprehensive turbulence-chemistry interaction models. Laser-based measurements are thus essential in this configuration, with this dataset still beyond replication by DNS due to the substantial computational resources required and the subsequent need for simplifications in geometry, chemistry, inlet conditions and/or species transport.

\subsection{Heat Release Rate Imaging}

Analyses of simultaneous PLIF images can provide insight into the structure of flames, such as the effect of weakening reaction zones (Medwell et al., 2009b) or estimations of normalized heat release rate (Paul and Najm, 1998; Gordon et al., 2009). Distributions of heat release rate are based on the assumption that the formation of $\mathrm{HCO}$ from $\mathrm{OH}$ and $\mathrm{CH}_{2} \mathrm{O}$ is the dominant exothermic reaction in the flame (Paul and Najm, 1998; Gordon et al., 2009). It follows that the overlap between $\mathrm{OH}$ and $\mathrm{CH}_{2} \mathrm{O}$ distributions (or $n_{\mathrm{OH}} \times n_{\mathrm{CH}_{2} \mathrm{O}}$ ) may be used to provide an estimation of the relative, local heat release rate. In practice, this analysis further assumes that the true concentration of $\mathrm{CH}_{2} \mathrm{O}$ scales linearly with the normalized $\mathrm{CH}_{2} \mathrm{O}$ after quenching and Boltzmann fraction approximations described previously. This analysis was initially performed in $\mathrm{CH}_{4} / \mathrm{NG}$ flames (Paul and Najm, 1998; Gordon et al., 2009), and has been supported by numerical simulations (Gordon et al., 2009; Sidey et al., 2016). The interpretation of $n_{\mathrm{OH}} \times n_{\mathrm{CH}_{2} \mathrm{O}}$ being representative of heat release rate has also been used in the analysis of dimethyl ether (DME) (Macfarlane et al., 2017, 2018), which is shown with chemiluminescence imaging in Figure 8. Although both $\mathrm{OH}$ and $\mathrm{CH}_{2} \mathrm{O}$ are routinely imaged using PLIF, their overlap may not always provide a suitable combination for estimating heat release rate, particularly in the MILD combustion regime (Sidey and Mastorakos, 2016). This has been confirmed numerically for flames with $n$-heptane (Ye et al., 2017), as well as both $\mathrm{C}_{2} \mathrm{H}_{4}$ and 1:1 $\mathrm{CH}_{4} / \mathrm{H}_{2}$ (by volume), with the product of $\mathrm{OH}$ and $\mathrm{HO}_{2}$ proposed as a heat release rate marker for the latter two fuels (Evans et al., 2017b).

\subsection{Current Directions}

Laser-based studies of gaseous fuelled-flames in the JHC configuration have included hydrogen, methane, ethylene, propane, acetone, ethanol and its isomer dimethyl-ether, nheptane, toluene, octan-1-ol and its isomer di-n-butyl-ether and larger hydrocarbons (Cabra et al., 2002, 2005; Dally et al., 2002; Medwell et al., 2007, 2008, 2009b; Oldenhof et al., 2010, 2011; Arndt et al., 2012, 2013, 2016; Medwell and Dally, 2012a; Papageorge et al., 2014; Walters, 2016; Ye et al., 2016, 2017, 2018; Evans et al., 2017b; Kruse et al., 2019), whilst only methanol (Wang et al., 2019b), and ethanol (Correia Rodrigues et al., 2015a,b) have been investigated in liquid spray flames due to the added complexity of diagnostics in two-phase flows. It is also noteworthy that there has been little research of either gaseous or spray flames at elevated pressures (Evans et al., 2019a), although it has been noted that there are both very few high quality datasets under these conditions, and a particular need for measurements pertaining to soot formation in liquid spray flames (Hochgreb, 2019). This is due to the technical challenges involved in the development of both appropriate facilities and diagnostic tools.

Laser diagnostics have proven to be a valuable tool in understanding flames in JHC burners. Laser diagnostics have identified phenomena which have not yet been replicated by numerical modeling which promotes the need for further, high quality measurements in canonical and poorly understood configurations. 


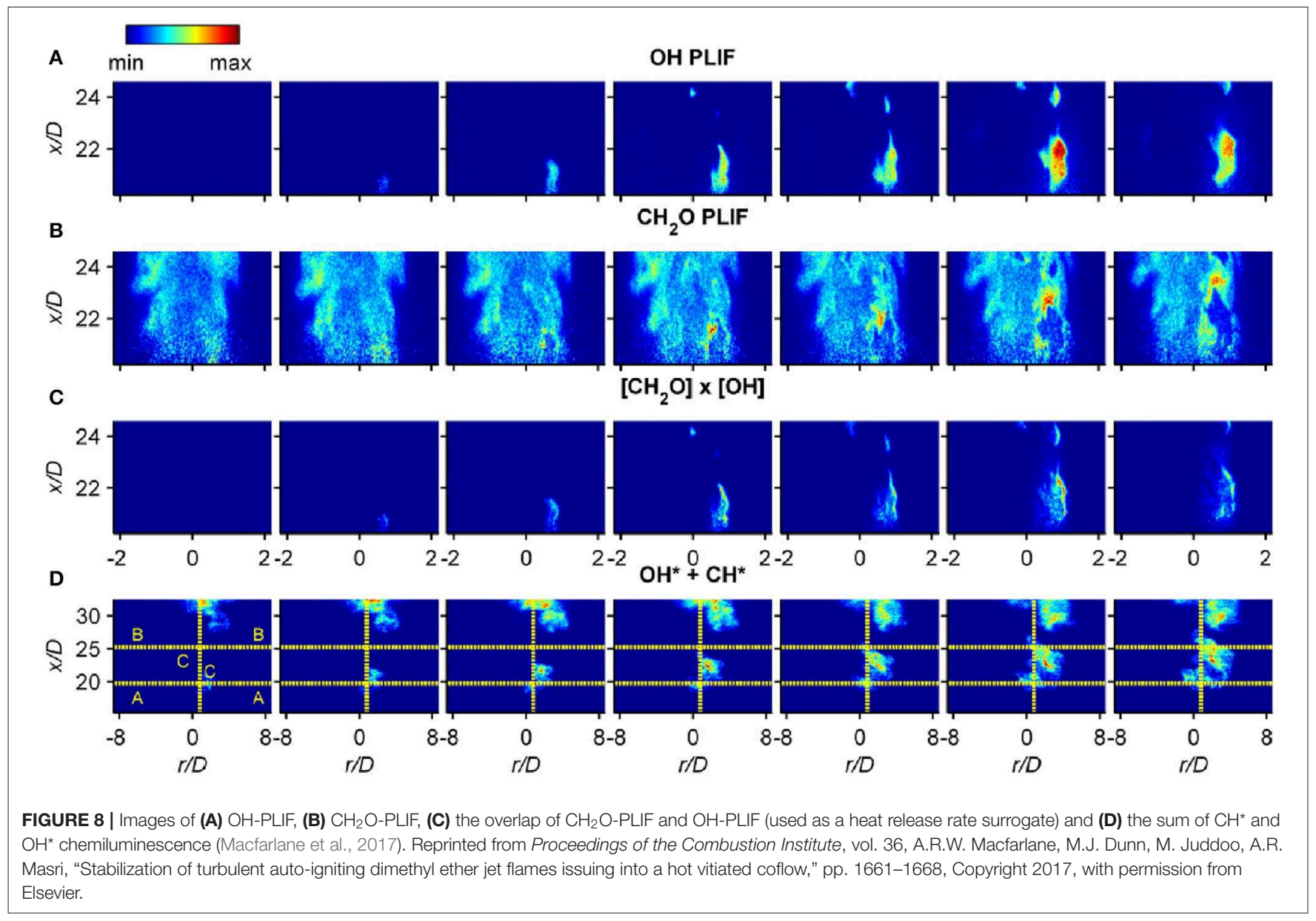

\section{ONGOING AND FUTURE CHALLENGES}

Optical diagnostics of flames in JHC burners have revealed a wealth of information about the ignition and structure of flames in hot and diluted environments. There are, however, ongoing challenges particularly for measurements in confined burners. These include:

- Measurements of mixture fraction have not been undertaken in transitional flames stabilized in JHC burners, despite such data having been taken in similar MILD (Dally et al., 2002) and autoignitive (Cabra et al., 2002, 2005; Dunn et al., 2009; Dunn et al., 2010) flames. Quantitative Rayleigh-Raman or polarized/depolarized Rayleigh scattering (Fielding et al., 2002; Frank et al., 2002; Schießl et al., 2009) measurements extending from the jet exit plane of a JHC burner to beyond the weak-to-strong transition would provide further insight into the ignition processes in MILD combustion and transitional flames and the downstream evolution of the reaction zone.

- Planar imaging of scalar dissipation has been performed in a variety of lifted and partially premixed flames using Rayleigh-Raman (Masri et al., 1996; Barlow et al., 2005) and polarized/depolarized Rayleigh scattering (Fielding et al., 2002; Frank et al., 2002; Schießl et al., 2009). Although gradients of temperature have been imaged in partially premixed flames stabilized on JHC burners (Dunn et al., 2007b; Gordon et al., 2009), semi-quantified or normalized measurements of scalar dissipation in non-premixed flames stabilized in hot and diluted coflows with $\mathrm{O}_{2}$ concentrations $\leq 6 \%$ would provide insight into the structure of the reaction zone in MILD combustion conditions and the non-monotonic trends in flame stabilization evident from OH-PLIF.

- Practical implementation of MILD combustion in interturbine burners (ITBs) requires an improved understanding and modeling capability of turbulence-chemistry interactions at elevated pressures. These both require high quality, quantified experimental data. The acquisition of these data presents a number of challenges, not least the requirement of optical diagnostics suitable for confined, high-pressure JHC burners. Flames in such pressurized burners are implicitly confined-increasing background scatter and beam-steering effects-and are more susceptible to PAH and soot formation and soot growth (Karataş and Ömer L. Gülder, 2012), which may limit the efficacy and validity of simultaneous quantitative diagnostics. Additional quantification challenges in these conditions include the evaluation of quenching of different fluorescent and seeded species at elevated pressures and the need to resolve smaller Kolmogorov length-scales resulting from increased gas densities. 
- The vast majority of studies performed in JHC burners have focussed on gaseous fuels. This is despite most transport fuels being carried and injected in the liquids phase. Although several studies of complex prevaporized liquid fuels have been undertaken in coflows with 3-9\% $\mathrm{O}_{2}$ (by vol.), only simple liquid spray flames have been the focus of laser-based diagnostic studies. Extension of laser-based studies to liquid, and additionally solid, fuels using techniques established for sooting (Chan Q. et al., 2011; Chan Q. N. et al., 2011) and swirling (Evans et al., 2019d) or piloted spray (Medwell et al., 2013) flames.

- Rayleigh scattering has been central to the success of optical diagnostics of flames stabilized in JHC burners. This is currently the only diagnostic approach which can provide planar measurements of temperature without limitations of selected species formation or the requirement of particle seeding. Without modification this technique cannot be applied to confined or particle or droplet laden flames. Two modifications to the Rayleigh scattering technique include filtered Rayleigh scattering (Hofmann and Leipert, 1996; Kearney et al., 2005) and the use of structured laser illumination planar imaging (SLIPI) (Aldén et al., 2011; Kempema and Long, 2014; Kristensson et al., 2015) which offer the potential solutions to the removal of Mie and unstructured background scattering, respectively. These or other techniques to measure the temperature field-such as the extension of CARS to line and planar measurements or combinations of two-color diagnostics suitable to low temperatures and a broad range of mixture fractions-will facilitate the collection of quantitative experimental data for absolute measurements and the further development of conditional statistics.

- Many current numerical combustion models cannot reliably predict the structure of flames stabilized in JHC burners without tuning of turbulence-chemistry interaction model constants or physical parameters (De et al., 2011; Evans et al., 2015a, 2019c; Parente et al., 2016; Ferrarotti et al., 2019), although recent LES have (Li et al., 2019) demonstrated less sensitivity than has been observed in equivalent RANS models (Wang et al., 2019a). Furthermore, these models are often calibrated using one or more of a limited set of high quality Rayleigh-Raman-LIF (Dally et al., 2002; Cabra et al., 2005), CARS-LIF-LDA (Oldenhof et al., 2010, 2011), or RayleighLIF (Medwell et al., 2008) data. Although these measurements have all targeted flames in JHC burners, they do not form a consistent dataset. This reinforces the ongoing need for high quality measurements in validation configurations, with an emphasis on the systematic variation of boundary conditions, to provide individual cases and trends which challenge current numerical modeling approaches.

\section{REFERENCES}

Aldén, M., Bood, J., Li, Z., and Richter, M. (2011). Visualization and understanding of combustion processes using spatially and temporally resolved laser diagnostic techniques. Proc. Combust. Inst. 33, 69-97. doi: 10.1016/j.proci.2010.09.004

\section{CONCLUSIONS}

The interactions between light and matter form the basis of laser diagnostics in flames. This review provides fundamental background and guidance to aid in the interpretation of laser-based measurements, whilst highlighting findings from experimental studies of flames in jet in hot coflow burners. This review has discussed the importance of laser-induced fluorescence, velocimetry, Rayleigh and Raman scattering measurements in studies of JHC burners, and highlighted potential techniques needed to meet future challenges in diagnostics.

The findings presented in this review reinforce the advantages of, and ongoing need for, laser-based diagnostics of flames to fill knowledge gaps which cannot be addressed by modeling or theory alone. Laser-based diagnostics have been used to identify different flame stabilization mechanisms in JHC burners, including ignition kernels and weak-to-strong transitions. These measurements have been supplemented with numerical analyses, however measurements of instantaneous mixture fraction, strain-rate and scalar dissipation would still be required to answer outstanding questions about flame structure and discontinuities in the flame sheet under a narrow range of conditions.

There is still a need to better understand flame stabilization and structure in JHC burners in environments better representing practical systems. The challenges these environments present to current modeling approaches and the lack of appropriate validation data cements the importance of laser-based measurements, and the ongoing need to continue to develop the capabilities of laser diagnostics.

\section{AUTHOR CONTRIBUTIONS}

Both authors jointly drafted the outline of the work and discussed the content and contribution. ME produced the initial draft and revisions (scientific, grammatical, and stylistic) were made by both authors.

\section{FUNDING}

Financial salary support provided to ME by the Australian Research Council through the Discovery Projects Programme.

\section{ACKNOWLEDGMENTS}

The authors thank Prof. Bassam Dally and Dr. Alfonso Chinnici of the University of Adelaide for their helpful discussions. The authors also acknowledge support from The University of Adelaide and financial support from the Australian Research Council.

Arndt, C., Gounder, J., Meier, W., and Aigner, M. (2012). Auto-ignition and flame stabilization of pulsed methane jets in a hot vitiated coflow studied with high-speed laser and imaging techniques. Appl. Phys. B 108, 407-417. doi: 10.1007/s00340-012-4945-5

Arndt, C. M., Papageorge, M. J., Fuest, F., Sutton, J. A., and Meier, W. (2019). Experimental investigation of the auto-ignition of a 
transient propane jet-in-hot-coflow. Proc. Combust. Inst. 37, 2117-2124. doi: 10.1016/j.proci.2018.06.195

Arndt, C. M., Papageorge, M. J., Fuest, F., Sutton, J. A., Meier, W., and Aigner, M. (2016). The role of temperature, mixture fraction, and scalar dissipation rate on transient methane injection and auto-ignition in a jet in hot coflow burner. Combust. Flame 167, 60-71. doi: 10.1016/j.combustflame.2016.02.027

Arndt, C. M., Schießl, R., Gounder, J. D., Meier, W., and Aigner, M. (2013). Flame stabilization and auto-ignition of pulsed methane jets in a hot coflow: influence of temperature. Proc. Combust. Inst. 34, 1483-1490. doi: 10.1016/j.proci.2012.05.082

Ayoola, B., Balachandran, R., Frank, J., Mastorakos, E., and Kaminski, C. (2006). Spatially resolved heat release rate measurements in turbulent premixed flames. Combust. Flame 144, 1-16. doi: 10.1016/j.combustflame.2005.06.005

Barlow, R., Fiechtner, G., Carter, C., and Chen, J.-Y. (2000). Experiments on the scalar structure of turbulent $\mathrm{CO} / \mathrm{H}_{2} / \mathrm{N}_{2}$ jet flames. Combust. Flame 120, 549-569. doi: 10.1016/S0010-2180(99)00126-1

Barlow, R., Frank, J., Karpetis, A., and Chen, J.-Y. (2005). Piloted methane/air jet flames: transport effects and aspects of scalar structure. Combust. Flame 143, 433-449. doi: 10.1016/j.combustflame.2005.08.017

Barlow, R., Meares, S., Magnotti, G., Cutcher, H., and Masri, A. (2015). Local extinction and near-field structure in piloted turbulent $\mathrm{CH}_{4} /$ air jet flames with inhomogeneous inlets. Combust. Flame 162, 3516-3540. doi: 10.1016/j.combustflame.2015.06.009

Barlow, R. S. (2007). Laser diagnostics and their interplay with computations to understand turbulent combustion. Proc. Combust. Inst. 31, 49-75. doi: 10.1016/j.proci.2006.08.122

Barlow, R. S., Dunn, M. J., Sweeney, M. S., and Hochgreb, S. (2012). Effects of preferential transport in turbulent bluff-body-stabilized lean premixed $\mathrm{CH}_{4}$ /air flames. Combust. Flame 159, 2563-2575. doi: 10.1016/j.combustflame.2011.11.013

Bartos, D., Dunn, M., Sirignano, M., D’Anna, A., and Masri, A. R. (2017). Tracking the evolution of soot particles and precursors in turbulent flames using laser-induced emission. Proc. Combust. Inst. 36, 1869-1876. doi: $10.1016 /$ j.proci.2016.07.092

Bilger, R., Stårner, S., and Kee, R. (1990). On reduced mechanisms for methane - air combustion in nonpremixed flames. Combust. Flame 80, 135-149. doi: 10.1016/0010-2180(90)90122-8

Bohlin, A., and Kliewer, C. J. (2014). Diagnostic imaging in flames with instantaneous planar coherent Raman spectroscopy. J. Phys. Chem. Lett. 5, 1243-1248. doi: 10.1021/jz500384y

Borggren, J., Weng, W., Hosseinnia, A., Bengtsson, P.-E., Aldén, M., and Li, Z. (2017). Diode laser-based thermometry using two-line atomic fluorescence of indium and gallium. Appl. Phys. B 123:278. doi: 10.1007/s00340-017-6855-Z

Cabra, R., Chen, J.-Y., Dibble, R., Karpetis, A., and Barlow, R. (2005). Lifted methane-air jet flames in a vitiated coflow. Combust. Flame 143, 491-506. doi: 10.1016/j.combustflame.2005.08.019

Cabra, R., Myhrvold, T., Chen, J., Dibble, R., Karpetis, A., and Barlow, R. (2002). Simultaneous laser Raman-Rayleigh-LIF measurements and numerical modeling results of a lifted turbulent $\mathrm{H}_{2} / \mathrm{N}_{2}$ jet flame in a vitiated coflow. Proc. Combust. Inst. 29, 1881-1888. doi: 10.1016/S1540-7489(02)80228-0

Carter, C. D., and Barlow, R. S. (1994). Simultaneous measurements of NO, $\mathrm{OH}$, and the major species in turbulent flames. Opt. Lett. 19, 299-301. doi: 10.1364/OL.19.000299

Cavaliere, A., and de Joannon, M. (2004). Mild combustion. Prog. Energ. Combust. 30, 329-366. doi: 10.1016/j.pecs.2004.02.003

Cavaliere, D. E., Kariuki, J., and Mastorakos, E. (2013). A comparison of the blowoff behaviour of swirl-stabilized premixed, non-premixed and spray flames. Flow Turbul. Combust. 91, 347-372. doi: 10.1007/s10494-013-9470-Z

Chan, Q., Medwell, P., Alwahabi, Z., Dally, B., and Nathan, G. (2011). Assessment of interferences to nonlinear two-line atomic fluorescence (NTLAF) in sooty flames. Appl. Phys. B 104, 189-198. doi: 10.1007/s00340-011-4497-0

Chan, Q. N., Medwell, P. R., Dally, B. B., Alwahabi, Z. T., and Nathan, G. J. (2012). New seeding methodology for gas concentration measurements. Appl. Spectrosc. 66, 803-809. doi: 10.1366/11-06553

Chan, Q. N., Medwell, P. R., Kalt, P. A., Alwahabi, Z. T., Dally, B. B., and Nathan, G. J. (2011). Simultaneous imaging of temperature and soot volume fraction. Proc. Combust. Inst. 33, 791-798. doi: 10.1016/j.proci.2010.06.031

Chan, Q. N., Medwell, P. R., Kalt, P. A. M., Alwahabi, Z. T., Dally, B. B., and Nathan, G. J. (2010). Solvent effects on two-line atomic fluorescence of indium. Appl. Opt. 49, 1257-1266. doi: 10.1364/AO.49.001257
Correia Rodrigues, H., Tummers, M., van Veen, E., and Roekaerts, D. (2015a). Effects of coflow temperature and composition on ethanol spray flames in hot-diluted coflow. Int. J. Heat Fluid Flow 51, 309-323. doi: 10.1016/j.ijheatfluidflow.2014.10.006

Correia Rodrigues, H., Tummers, M. J., van Veen, E. H., and Roekaerts, D. J. (2015b). Spray flame structure in conventional and hot-diluted combustion regime. Combust. Flame 162, 759-773. doi: 10.1016/j.combustflame.2014.07.033

Dally, B., Karpetis, A., and Barlow, R. (2002). Structure of turbulent nonpremixed jet flames in a diluted hot coflow. Proc. Combust. Inst. 29, 1147-1154. doi: 10.1016/S1540-7489(02)80145-6

Dally, B., Riesmeier, E., and Peters, N. (2004). Effect of fuel mixture on moderate and intense low oxygen dilution combustion. Combust. Flame 137, 418-431. doi: 10.1016/j.combustflame.2004.02.011

de Joannon, M., Sabia, P., Cozzolino, G., Sorrentino, G., and Cavaliere, A. (2012). Pyrolitic and oxidative structures in hot oxidant diluted oxidant (HODO) MILD combustion. Combust. Sci. Technol. 184, 1207-1218. doi: 10.1080/00102202.2012.664012

De, A., Oldenhof, E., Sathiah, P., and Roekaerts, D. (2011). Numerical simulation of delft-jet-in-hot-coflow (DJHC) flames using the eddy dissipation concept model for turbulence-chemistry interaction. Flow Turbul. Combust. 87, 537-567. doi: 10.1007/s10494-011-9337-0

Doan, N., and Swaminathan, N. (2019). Role of radicals on MILD combustion inception. Proc. Comb. Inst. 37, 4539-4546. doi: 10.1016/j.proci.2018. 07.038

Döbbeling, K., Hellat, J., and Koch, H. (2007). 25 years of BBC/ABB/Alstom lean premix combustion technologies. J. Eng. Gas Turb. Power 1, 2-12. doi: $10.1115 / 1.2181183$

Dunn, M., and Masri, A. (2010). A comprehensive model for the quantification of linear and nonlinear regime laser-induced fluorescence of $\mathrm{OH}$ under $\mathrm{A}^{2} \Sigma^{+} \leftarrow \mathrm{X}^{2} \Pi(1,0)$ excitation. Appl. Phys. B 101, 445-463. doi: 10.1007/s00340-010-4129-0

Dunn, M., Masri, A., Bilger, R., Barlow, R., and Wang, G.-H. (2009). The compositional structure of highly turbulent piloted premixed flames issuing into a hot coflow. Proc. Combust. Inst. 32, 1779-1786. doi: $10.1016 /$ j.proci.2008.08.007

Dunn, M. J. (2008). Finite-rate chemistry effects in turbulent premixed combustion. (Ph.D. Thesis). School of Aeronautical, Mechanical and Mechatronic Engineering, The University of Sydney, Sydney, NSW, Australia.

Dunn, M. J., Masri, A. R., and Bilger, R. W. (2007a). A new piloted premixed jet burner to study strong finite-rate chemistry effects. Combust. Flame 151, 46-60. doi: 10.1016/j.combustflame.2007.05.010

Dunn, M. J., Masri, A. R., and Bilger, R. W. (2007b). "Lifted turbulent premixed flames issuing into a hot coflow, imaging of temperature and $\mathrm{OH}$," in 16th Australasian Fluid Mechanics Conference (AFMC) (Gold Coast, QLD: School of Engineering, The University of Queensland), 1344-1349.

Dunn, M. J., Masri, A. R., Bilger, R. W., and Barlow, R. S. (2010). Finite rate chemistry effects in highly sheared turbulent premixed flames. Flow Turbul. Combust. 85, 621-648. doi: 10.1007/s10494-010-9280-5

Duwig, C., Li, B., Li, Z., and Aldén, M. (2012). High resolution imaging of flameless and distributed turbulent combustion. Combust. Flame 159, 306-316. doi: 10.1016/j.combustflame.2011.06.018

Eckbreth, A. C. (1996). Laser Diagnostics for Combustion Temperature and Species, Volume 3 of Combustion Science and Technology, 2nd Edn. Amsterdam: CRC Press.

Evans, M. J., Chinnici, A., Medwell, P. R., and Ye, J. (2017a). Ignition features of methane and ethylene fuel-blends in hot and diluted coflows. Fuel 203, 279-289. doi: 10.1016/j.fuel.2017.04.113

Evans, M. J., Medwell, P. R., and Chan, Q. N. (2019a). "Commissioning a confined and pressurised jet in hot and vitiated coflow burner," in 11th Mediterranean Combustion Symposium (Tenerife).

Evans, M. J., Medwell, P. R., Sun, Z., Chinnici, A., Ye, J., Chan, Q. N., et al. (2019b). Downstream evolution of $n$-heptane/toluene flames in hot and vitiated coflows. Combust. Flame 202, 78-89. doi: 10.1016/j.combustflame.2019.01.008

Evans, M. J., Medwell, P. R., and Tian, Z. F. (2015a). Modeling lifted jet flames in a heated coflow using an optimized eddy dissipation concept model. Combust. Sci. Technol. 187, 1093-1109. doi: 10.1080/00102202.2014.1002836

Evans, M. J., Medwell, P. R., Tian, Z. F., Frassoldati, A., Cuoci, A., and Stagni, A. (2016a). Ignition characteristics in spatially zero-, one- and two-dimensional laminar ethylene flames. AIAA J. 54, 3255-3264. doi: 10.2514/1.J054958 
Evans, M. J., Medwell, P. R., Tian, Z. F., Ye, J., Frassoldati, A., and Cuoci, A. (2017b). Effects of oxidant stream composition on non-premixed laminar flames with heated and diluted coflows. Combust. Flame 178, 297-310. doi: 10.1016/j.combustflame.2016.12.023

Evans, M. J., Medwell, P. R., Wu, H., Stagni, A., and Ihme, M. (2016b). Classification and lift-off height prediction of non-Premixed MILD and autoignitive flames. Proc. Combust. Inst. 36, 4297-4304. doi: 10.1016/j.proci.2016.06.013

Evans, M. J., Medwell, P. R., and Ye, J. (2015b). "Laser-induced fluorescence of hydroxyl in ethylene jet flames in hot and diluted coflows," in 7th Australian Conference on Laser Diagnostics in Fluid Mechanics and Combustion (Melbourne, VIC).

Evans, M. J., Petre, C., Medwell, P. R., and Parente, A. (2019c). Generalisation of the eddy-dissipation concept for jet flames with low turbulence and low Damköhler number. Proc. Combust. Inst. 37, 4497-4505. doi: 10.1016/j.proci.2018.06.017

Evans, M. J., Sidey, J. A., Ye, J., Medwell, P. R., Dally, B. B., and Mastorakos, E. (2019d). Temperature and reaction zone imaging in turbulent swirling dual-fuel flames. Proc. Combust. Inst. 37, 2159-2166. doi: 10.1016/j.proci.2018.07.076

Ferrarotti, M., Li, Z., and Parente, A. (2019). On the role of mixing models in the simulation of mild combustion using finite-rate chemistry combustion models. Proc. Combust. Inst. 37, 4531-4538. doi: 10.1016/j.proci.2018.07.043

Fielding, J., Frank, J. H., Kaiser, S. A., Smooke, M. D., and Long, M. B. (2002). Polarized/depolarized Rayleigh scattering for determining fuel concentrations in flames. Proc. Combust. Inst. 29, 2703-2709. doi: 10.1016/S1540-7489(02)80329-7

Foo, K. K., Evans, M. J., Sun, Z., Medwell, P. R., Alwahabi, Z. T., Nathan, G. J., et al. (2019). Calculated concentration distributions and time histories of key species in an acoustically forced laminar flame. Combust. Flame 204, 189-203. doi: 10.1016/j.combustflame.2019.03.019

Foo, K. K., Sun, Z., Medwell, P. R., Alwahabi, Z. T., Dally, B. B., and Nathan, G. J. (2017). Experimental investigation of acoustic forcing on temperature, soot volume fraction and primary particle diameter in non-premixed laminar flames. Combust. Flame 181, 270-282. doi: 10.1016/j.combustflame.2017.04.002

Foo, K. K., Sun, Z., Medwell, P. R., Alwahabi, Z. T., Nathan, G. J., and Dally, B. B. (2018). Influence of nozzle diameter on soot evolution in acoustically forced laminar non-premixed flames. Combust. Flame 194, 376-386. doi: 10.1016/j.combustflame.2018.05.026

Frank, J., and Barlow, R. (1998). Simultaneous Rayleigh, Raman, and LIF measurements in turbulent premixed methane-air flames. Proc. Combust. Inst. 27, 759-766. doi: 10.1016/S0082-0784(98)80470-0

Frank, J. H., Kaiser, S. A., and Long, M. B. (2002). Reaction-rate, mixture-fraction, and temperature imaging in turbulent methane/air jet flames. Proc. Combust. Inst. 29, 2687-2694. doi: 10.1016/S1540-7489(02)80327-3

Frank, J. H., Kalt, P. A., and Bilger, R. W. (1999). Measurements of conditional velocities in turbulent premixed flames by simultaneous OH PLIF and PIV. Combust. Flame 116, 220-232. doi: 10.1016/S0010-2180(98)00041-8

Fuest, F., Barlow, R. S., Chen, J.-Y., and Dreizler, A. (2012). Raman/Rayleigh scattering and CO-LIF measurements in laminar and turbulent jet flames of dimethyl ether. Combust. Flame 159, 2533-2562. doi: 10.1016/j.combustflame.2011.11.001

Gabet, K. N., and Sutton, J. A. (2014). Narrowband versus broadband excitation for $\mathrm{CH}_{2} \mathrm{O}$ PLIF imaging in flames using a frequency-tripled nd:yag laser. Exp. Fluids 55:1774. doi: 10.1007/s00348-014-1774-9

Galletti, C., Parente, A., and Tognotti, L. (2007). Numerical and experimental investigation of a mild combustion burner. Combust. Flame 151, 649-664. doi: 10.1016/j.combustflame.2007.07.016

Giezendanner-Thoben, R., Meier, U., Meier, W., Heinze, J., and Aigner, M. (2005). Phase-locked two-line $\mathrm{OH}$ planar laser-induced fluorescence thermometry in a pulsating gas turbine model combustor at atmospheric pressure. Appl. Opt. 44, 6565-6577. doi: 10.1364/AO.44.006565

Gordon, R. L., Masri, A. R., and Mastorakos, E. (2008). Simultaneous Rayleigh temperature, $\mathrm{OH}$ - and $\mathrm{CH}_{2} \mathrm{O}$-LIF imaging of methane jets in a vitiated coflow. Combust. Flame 155, 181-195. doi: 10.1016/j.combustflame.2008.07.001

Gordon, R. L., Masri, A. R., and Mastorakos, E. (2009). Heat release rate as represented by $[\mathrm{OH}] \times[\mathrm{CH} 2 \mathrm{O}]$ and its role in autoignition. Combust. Theor. Model. 13, 645-670. doi: 10.1080/13647830902957200
Gordon, R. L., Masri, A. R., Pope, S. B., and Goldin, G. M. (2007). A numerical study of auto-ignition in turbulent lifted flames issuing into a vitiated co-flow. Combust. Theor. Model. 11, 351-376. doi: 10.1080/13647830600903472

Gu, D., Sun, Z., Dally, B. B., Medwell, P. R., Alwahabi, Z. T., and Nathan, G. J. (2017). Simultaneous measurements of gas temperature, soot volume fraction and primary particle diameter in a sooting lifted turbulent ethylene/air non-premixed flame. Combust. Flame 179, 33-50. doi: 10.1016/j.combustflame.2017.01.017

Gu, D. H., Sun, Z. W., Medwell, P. R., Alwahabi, Z. T., Dally, B. B., and Nathan, G. J. (2015). Mechanism for laser-induced fluorescence signal generation in a nanoparticle-seeded flow for planar flame thermometry. Appl. Phys. B 118, 209-218. doi: 10.1007/s00340-014-5972-1

Hochgreb, S. (2019). Mind the gap: turbulent combustion model validation and future needs. Proc. Combust. Inst. 37, 2091-2107. doi: 10.1016/j.proci.2018.05.003

Hofmann, D., and Leipert, A. (1996). Temperature field measurements in a sooting flame by filtered Rayleigh scattering (FRS). Proc. Combust. Inst. 26, 945-950. doi: 10.1016/S0082-0784(96)80306-7

Honoré, D., Lecordier, B., Susset, A., Jaffré, D., Perrin, M., Most, J., and Trinite, M. (2000). Time-resolved particle image velocimetry in confined bluff-body burner flames. Exp. Fluids 29, S248-S254. doi: 10.1007/s003480070027

Ihme, M., and See, Y. C. (2011). LES flamelet modeling of a three-stream MILD combustor: Analysis of flame sensitivity to scalar inflow conditions. Proc. Combust. Inst. 33, 1309-1217. doi: 10.1016/j.proci.2010.05.019

Ihme, M., Zhang, J., He, G., and Dally, B. B. (2012). Large-eddy simulation of a jet-in-hot-coflow burner operating in the oxygen-diluted combustion regime. Flow Turbul. Combust. 89, 449-464. doi: 10.1007/s10494-012-9399-7

Jiang, N., Hsu, P. S., Mance, J. G., Wu, Y., Gragston, M., Zhang, Z., et al. (2017). High-speed 2D Raman imaging at elevated pressures. Opt. Lett. 42, 3678-3681. doi: 10.1364/OL.42.003678

Kähler, C. J., Scharnowski, S., and Cierpka, C. (2012). On the resolution limit of digital particle image velocimetry. Exp. Fluids 52, 1629-1639. doi: 10.1007/s00348-012-1280-x

Kaiser, S. A., and Frank, J. H. (2011). The effects of laser-sheet thickness on dissipation measurements in turbulent non-reacting jets and jet flames. Meas. Sci. Technol. 22:045403. doi: 10.1088/0957-0233/22/4/045403

Kamal, M. M., Zhou, R., Balusamy, S., and Hochgreb, S. (2015). Favreand reynolds-averaged velocity measurements: interpreting PIV and LDA measurements in combustion. Proc. Combust. Inst. 35, 3803-3811. doi: 10.1016/j.proci.2014.06.061

Karataş, A. E., and Ömer L. Gülder (2012). Soot formation in high pressure laminar diffusion flames. Prog. Energ. Combust. Sci. 38, 818-845. doi: 10.1016/j.pecs.2012.04.003

Karpetis, A., and Barlow, R. (2002). Measurements of scalar dissipation in a turbulent piloted methane/air jet flame. Proc. Combust. Inst. 29, 1929-1936. doi: 10.1016/S1540-7489(02)80234-6

Kawazoe, H., Ohsawa, K., and Fujikake, K. (1990). LDA measurement of fuel droplet sizes and velocities in a combustion field. Combust. Flame 82, 151-162. doi: 10.1016/0010-2180(90)90094-8

Kearney, S. P., Schefer, R. W., Beresh, S. J., and Grasser, T. W. (2005). Temperature imaging in nonpremixed flames by joint filtered Rayleigh and Raman scattering. Appl. Opt. 44, 1548-1558. doi: 10.1364/AO.44.001548

Kelman, J. B., Eltobaji, A. J., and Masri, A. R. (1998). Laser imaging in the stabilisation region of turbulent lifted flames. Combust. Sci. Technol. 135, 117-134. doi: 10.1080/00102209808924153

Kempema, N. J., and Long, M. B. (2014). Quantitative Rayleigh thermometry for high background scattering applications with structured laser illumination planar imaging. Appl. Opt. 53, 6688-6697. doi: 10.1364/AO.53.006688

Kohse-Höinghaus, K. and Jeffries, J. B., editors (2002). Applied Combustion Diagnostics. New York, NY: Taylor \& Francis.

Kojima, J., and Nguyen, Q.-V. (2002). Laser pulse-stretching with multiple optical ring cavities. Appl. Opt. 41, 6360-6370. doi: 10.1364/AO.41.0 06360

Kristensson, E., Ehn, A., Bood, J., and Aldén, M. (2015). Advancements in Rayleigh scattering thermometry by means of structured illumination. Proc. Combust. Inst. 35, 3689-3696. doi: 10.1016/j.proci.2014.06.056

Kruse, S., Medwell, P., Beeckmann, J., and Pitsch, H. (2018). The significance of beam steering on laser-induced incandescence measurements in laminar counterflow flames. Appl. Phys. B 124:212. doi: 10.1007/s00340-018-7072-0 
Kruse, S., Ye, J., Sun, Z., Attili, A., Dally, B., Medwell, P., and Pitsch, H. (2019). Experimental investigation of soot evolution in a turbulent nonpremixed prevaporized toluene flame. Proc. Combust. Inst. 37, 849-857. doi: 10.1016/j.proci.2018.05.075

Kyritsis, D. C., Santoro, V. S., and Gomez, A. (2004). The effect of temperature correction on the measured thickness of formaldehyde zones in diffusion flames for $355 \mathrm{~nm}$ excitation. Exp. Fluids 37, 769-772. doi: 10.1007/s00348-004-0860-9

Li, Z., Cuoci, A., and Parente, A. (2019). Large eddy Simulation of MILD combustion using finite rate chemistry: Effect of combustion sub-grid closure. Proc. Combust. Inst. 37, 4519-4529. doi: 10.1016/j.proci.2018.09.033

Luo, Z., Yoo, C. S., Richardson, E. S., Chen, J. H., Law, C. K., and Lu, T. (2012). Chemical explosive mode analysis for a turbulent lifted ethylene jet flame in highly-heated coflow. Combust. Flame 159, 265-274. doi: 10.1016/j.combustflame.2011.05.023

Lyons, K., Watson, K., Carter, C., and Donbar, J. (2005). On flame holes and local extinction in lifted-jet diffusion flames. Combust. Flame 142, 308-313. doi: 10.1016/j.combustflame.2005.04.006

Macfarlane, A., Dunn, M., Juddoo, M., and Masri, A. (2017). Stabilisation of turbulent auto-igniting dimethyl ether jet flames issuing into a hot vitiated coflow. Proc. Combust. Inst. 36, 1661-1668. doi: 10.1016/j.proci.2016.08.028

Macfarlane, A., Dunn, M., and Masri, A. (2019). The influence of fuel type and partial premixing on the structure and behaviour of turbulent autoigniting flames. Proc. Combust. Inst. 37, 2277-2285. doi: 10.1016/j.proci.2018.09.006

Macfarlane, A. R., Dunn, M., Juddoo, M., and Masri, A. (2018). The evolution of autoignition kernels in turbulent flames of dimethyl ether. Combust. Flame 197, 182-196. doi: 10.1016/j.combustflame.2018.07.022

Magnotti, G., and Barlow, R. (2017). Dual-resolution Raman spectroscopy for measurements of temperature and twelve species in hydrocarbon-air flames. Proc. Combust. Inst. 36, 4477-4485. doi: 10.1016/j.proci.2016.06.128

Makwana, A., Wang, Y., Iyer, S., Linevsky, M., Santoro, R. J., Litzinger, T. A., et al. (2018). Effect of fuel composition on soot and aromatic species distributions in laminar, co-flow flames. part 2. partially-premixed fuel. Combust. Flame 189, 456-471. doi: 10.1016/j.combustflame.2017.08.015

Mardani, A., Tabejamaat, S., and Mohammadi, M. B. (2011). Numerical study of the effect of turbulence on rate of reactions in the MILD combustion regime. Combust. Theor. Model. 15, 753-772. doi: 10.1080/13647830.2011.561368

Masri, A., Dibble, R., and Barlow, R. (1996). The structure of turbulent nonpremixed flames revealed by Raman-Rayleigh-LIF measurements. Prog. Energy Combust. Sci. 22, 307-362. doi: 10.1016/S0360-1285(96)00009-3

Masri, A., Kelman, J., and Dally, B. (1998). The instantaneous spatial structure of the recirculation zone in bluff-body stabilized flames. Proc. Combust. Inst. 27, 1031-1038. doi: 10.1016/S0082-0784(98)80503-1

Mastorakos, E. (2009). Ignition of turbulent non-premixed flames. Prog. Energy Combust. Sci. 35, 57-97. doi: 10.1016/j.pecs.2008.07.002

McMillin, B. K., Seitzman, J. M., and Hanson, R. K. (1994). Comparison of NO and $\mathrm{OH}$ planar fluorescence temperature measurements in scramjet model flowfield. AIAA J. 32, 1945-1952. doi: 10.2514/3.12237

Medwell, P. R., Chan, Q. N., Dally, B. B., Alwahabi, Z. T., Mahmoud, S., Metha, G. F., et al. (2012). Flow seeding with elemental metal species via an optical method. Appl. Phys. B 107, 665-668. doi: 10.1007/s00340-012-5065-y

Medwell, P. R., Chan, Q. N., Dally, B. B., Mahmoud, S., Alwahabi, Z. T., and Nathan, G. J. (2013). Temperature measurements in turbulent non-premixed flames by two-line atomic fluorescence. Proc. Combust. Inst. 34, 3619-3627. doi: 10.1016/j.proci.2012.06.027

Medwell, P. R., Chan, Q. N., Kalt, P. A. M., Alwahabi, Z. T., Dally, B. B., and Nathan, G. J. (2009a). Development of temperature imaging using two-line atomic fluorescence. Appl. Opt. 48, 1237-1248. doi: 10.1364/AO.48.001237

Medwell, P. R., Chan, Q. N., Kalt, P. A. M., Alwahabi, Z. T., Dally, B. B., and Nathan, G. J. (2010). Instantaneous temperature imaging of diffusion flames using two-line atomic fluorescence. Appl. Spectrosc. 64, 173-176. doi: 10.1366/000370210790619573

Medwell, P. R., and Dally, B. B. (2012a). Effect of fuel composition on jet flames in a heated and diluted oxidant stream. Combust. Flame 159, 3138-3145. doi: 10.1016/j.combustflame.2012.04.012

Medwell, P. R., and Dally, B. B. (2012b). Experimental observation of lifted flames in a heated and diluted coflow. Energy Fuels 26, 5519-5527. doi: $10.1021 / \mathrm{ef} 301029 \mathrm{u}$
Medwell, P. R., Evans, M. J., Chan, Q. N., and Katta, V. R. (2016). Laminar flame calculations for analysing trends in autoignitive jet flames in a hot and vitiated coflow. Energy Fuels 30, 8680-8690. doi: 10.1021/acs.energyfuels.6b01264

Medwell, P. R., Kalt, P. A. M., and Dally, B. B. (2007). Simultaneous imaging of $\mathrm{OH}$, formaldehyde, and temperature of turbulent nonpremixed jet flames in a heated and diluted coflow. Combust. Flame 148, 48-61. doi: 10.1016/j.combustflame.2006.10.002

Medwell, P. R., Kalt, P. A. M., and Dally, B. B. (2008). Imaging of diluted turbulent ethylene flames stabilized on a Jet in Hot Coflow (JHC) burner. Combust. Flame 152, 100-113. doi: 10.1016/j.combustflame.2007.09.003

Medwell, P. R., Kalt, P. A. M., and Dally, B. B. (2009b). Reaction zone weakening effects under hot and diluted oxidant stream conditions. Combust. Sci. Technol. 181, 937-953. doi: 10.1080/00102200902904138

Medwell, P. R., Masri, A. R., Pham, P. X., Dally, B. B., and Nathan, G. J. (2014), Temperature imaging of turbulent dilute spray flames using two-line atomic fluorescence. Exp. Fluids 55:1840. doi: 10.1007/s00348-014-1840-3

Minamoto, Y., and Swaminathan, N. (2014). Scalar gradient behaviour in MILD combustion. Combust. Flame 161, 1063-1075. doi: 10.1016/j.combustflame.2013.10.005

Minamoto, Y., Swaminathan, N., Cant, R. S., and Leung, T. (2014). Reaction zones and their structure in MILD combustion. Combust. Sci. Technol. 186, 1075-1096. doi: 10.1080/00102202.2014.902814

Mokhov, A., Gersen, S., and Levinsky, H. (2005). Spontaneous Raman measurements of acetylene in atmospheric-pressure methane/air flames. Chem. Phys. Lett. 403, 233-237. doi: 10.1016/j.cplett.2005.01.021

Mungal, M. G., Lourenco, L. M., and Krothapalli, A. (1995). Instantaneous velocity measurements in laminar and turbulent premixed flames using on-line PIV. Combust. Sci. Technol. 106, 239-265. doi: 10.1080/00102209508907781

Namer, I., and Schefer, R. (1985). Error estimates for Rayleigh scattering density and temperature measurements in premixed flames. Exp. Fluids 3, 1-9. doi: $10.1007 / \mathrm{BF} 00285264$

Nguyen, Q., Dibble, R., Carter, C., Fiechtner, G., and Barlow, R. (1996). Raman-LIF measurements of temperature, major species, $\mathrm{OH}$, and NO in a methane-air bunsen flame. Combust. Flame 105, 499-510. doi: 10.1016/0010-2180(96)00226-X

Oberlack, M., Arlitt, R., and Peters, N. (2000). On stochastic Damköhler number variations in a homogeneous flow reactor. Combust. Theor. Model. 4, 495-510. doi: 10.1088/1364-7830/4/4/307

Oldenhof, E., Tummers, M. J., van Veen, E. H., and Roekaerts, D. J. E. M. (2010). Ignition kernel formation and lift-off behaviour of jet-in-hot-coflow flames. Combust. Flame 157, 1167-1178. doi: 10.1016/j.combustflame.2010.01.002

Oldenhof, E., Tummers, M. J., van Veen, E. H., and Roekaerts, D. J. E. M. (2011). Role of entrainment in the stabilisation of jet-in-hot-coflow flames. Combust. Flame 158, 1553-1563. doi: 10.1016/j.combustflame.2010.12.018

Oldenhof, E., Tummers, M. J., van Veen, E. H., and Roekaerts, D. J. E. M. (2012). Transient response of the Delft jet-in-hot coflow flames. Combust. Flame 159, 697-706. doi: 10.1016/j.combustflame.2011.08.001

O'Loughlin, W., and Masri, A. (2011). A new burner for studying autoignition in turbulent dilute sprays. Combust. Flame 158, 1577-1590. doi: 10.1016/j.combustflame.2010.12.021

O'Loughlin, W., and Masri, A. R. (2012). The structure of the auto-ignition region of turbulent dilute methanol sprays issuing in a vitiated co-flow. Flow Turbul. Combust. 89, 13-35. doi: 10.1007/s10494-012-9388-x

Özdemir, İ. B., and Peters, N. (2001). Characteristics of the reaction zone in a combustor operating at mild combustion. Exp. Fluids 30, 683-695. doi: $10.1007 / \mathrm{s} 003480000248$

Palmer, J. L., and Hanson, R. K. (1996). Temperature imaging in a supersonic free jet of combustion gases with two-line OH fluorescence. Appl. Opt. 35, 485-499. doi: 10.1364/AO.35.000485

Papageorge, M., Arndt, C., Fuest, F., Meier, W., and Sutton, J. (2014). Highspeed mixture fraction and temperature imaging of pulsed, turbulent fuel jets auto-igniting in high-temperature, vitiated co-flows. Exp. Fluids 55:1763. doi: 10.1007/s00348-014-1763-z

Parente, A., Malik, M. R., Contino, F., Cuoci, A., and Dally, B. B. (2016). Extension of the eddy dissipation concept for turbulence/chemistry interactions to MILD combustion. Fuel 163, 98-111. doi: 10.1016/j.fuel.2015. 09.020 
Paul, P. H., and Najm, H. N. (1998). Planar laser-induced fluorescence imaging of flame heat release rate. Proc. Combust. Inst. 27, 43-50. doi: 10.1016/S0082-0784(98)80388-3

Perpignan, A. A., Rao, A. G., and Roekaerts, D. J. (2018). Flameless combustion and its potential towards gas turbines. Prog. Energy Combust. Sci. 69, 28-62. doi: 10.1016/j.pecs.2018.06.002

Plessing, T., Peters, N., and Wünning, J. G. (1998). Laseroptical investigation of highly preheated combustion with strong exhaust gas recirculation. Proc. Combust. Inst. 27, 3197-3204. doi: 10.1016/S0082-0784(98)80183-5

Ramachandran, A., Narayanaswamy, V., and Lyons, K. M. (2019). Observations on the role of auto-ignition in flame stabilization in turbulent nonpremixed jet flames in vitiated coflow. J. Eng. Gas Turb. Power 141:061018. doi: $10.1115 / 1.4042807$

Richardson, D. R., Jiang, N., Blunck, D. L., Gord, J. R., and Roy, S. (2016). Characterization of inverse diffusion flames in vitiated cross flows via twophoton planar laser-induced fluorescence of $\mathrm{CO}$ and 2-D thermometry. Combust. Flame 168, 270-285. doi: 10.1016/j.combustflame.2016.03.005

Roy, S., Gord, J. R., and Patnaik, A. K. (2010). Recent advances in coherent anti-Stokes Raman scattering spectroscopy: fundamental developments and applications in reacting flows. Prog. Energy Combust. Sci. 36, 280-306. doi: $10.1016 /$ j.pecs.2009.11.001

Sabia, P., de Joannon, M., Sorrentino, G., Giudicianni, P., and Ragucci, R. (2015). Effects of mixture composition, dilution level and pressure on autoignition delay times of propane mixtures. Chem. Eng. J. 277, 324-333. doi: 10.1016/j.cej.2015.04.143

Schießl, R., Kaiser, S., Long, M., and Maas, U. (2009). Application of reduced state spaces to laser-based measurements in combustion. Proc. Combust. Inst. 32, 887-894. doi: $10.1016 /$ j.proci.2008.05.063

Sepman, A., Mokhov, A., and Levinsky, H. (2013). Spatial structure and NO formation of a laminar methane-nitrogen jet in hot coflow under MILD conditions: a spontaneous Raman and LIF study. Fuel 103, 705-710. doi: 10.1016/j.fuel.2012.10.010

Shabanian, S. R., Medwell, P. R., Rahimi, M., Frassoldati, A., and Cuoci, A. (2013). Kinetic and fluid dynamic modeling of ethylene jet flames in diluted and heated oxidant stream combustion conditions. Appl. Therm. Eng. 52, 538-554. doi: 10.1016/j.applthermaleng.2012.12.024

Sidey, J., and Mastorakos, E. (2015). Visualization of MILD combustion from jets in cross-flow. Proc. Combust. Inst. 35, 3537-3545. doi: 10.1016/j.proci.2014.07.028

Sidey, J., and Mastorakos, E. (2017). Visualisation of turbulent swirling dual-fuel flames. Proc. Combust. Inst. 36, 1721-1727. doi: 10.1016/j.proci.2016.08.045

Sidey, J. A., Giusti, A., and Mastorakos, E. (2016). Simulations of laminar nonpremixed flames of kerosene with hot combustion products as oxidiser. Combust. Theor. Model. 20, 958-973. doi: 10.1080/13647830.2016.1201146

Sidey, J. A., and Mastorakos, E. (2016). Simulations of laminar non-premixed flames of methane with hot combustion products as oxidiser. Combust. Flame 163, 1-11. doi: 10.1016/j.combustflame.2015.07.034

Sirignano, M., Bartos, D., Conturso, M., Dunn, M., D’Anna, A., and Masri, A. R. (2017). Detection of nanostructures and soot in laminar premixed flames. Combust. Flame 176, 299-308. doi: 10.1016/j.combustflame.2016.10.009

Sorrentino, G., de Joannon, M., Sabia, P., Ragucci, R., and Cavaliere, A. (2017). Numerical investigation of the ignition and annihilation of $\mathrm{CH}_{4} / \mathrm{N}_{2} / \mathrm{O}_{2}$ mixtures under MILD operative conditions with detailed chemistry. Combust. Theor. Model. 21, 120-136. doi: 10.1080/13647830.2016.1220624

Sorrentino, G., Sabia, P., de Joannon, M., Cavaliere, A., and Ragucci, R. (2016). The effect of diluent on the sustainability of MILD combustion in a cyclonic burner. Flow Turbul. Combust. 96, 449-468. doi: 10.1007/s10494-015-9668-3

Sorrentino, G., Sabia, P., de Joannon, M., Ragucci, R., Cavaliere, A., Göktolga, U., et al. (2015). Development of a novel cyclonic flow combustion chamber for achieving MILD/flameless combustion. Energy Proc. 66, 141-144. doi: 10.1016/j.egypro.2015.02.079

Starner, S., Bilger, R., and Long, M. (1995). A method for contour-aligned smoothing of joint $2 \mathrm{~d}$ scalar images in turbulent flames. Combust Sci. Technol. 107, 195-203. doi: 10.1080/00102209508907802

Sturgess, G., Zelina, J., Shouse, D. T., and Roquemore, W. (2005). Emissions reduction technologies for military gas turbine engines. J. Propul. Power 21, 193-217. doi: $10.2514 / 1.6528$
Sutton, J. A., and Driscoll, J. F. (2004). Rayleigh scattering cross sections of combustion species at 266,355 , and $532 \mathrm{~nm}$ for thermometry applications. Opt. Lett. 29, 2620-2622. doi: 10.1364/OL.29.002620

van Veen, E. H., and Roekaerts, D. (2005). Thermometry for turbulent flames by coherent anti-Stokes Raman spectroscopy with simultaneous referencing to the modeless excitation profile. Appl. Opt. 44, 6995-7004. doi: 10.1364/AO.44.006995

Walters, E. M. (2016). Stability and liftoff of non-premixed large hydrocarbon flames in MILD conditions. (Masters thesis). College of Engineering, Oregon State University, Corvallis, OR, United States.

Wang, H., Zhou, H., Ren, Z., and Law, C. K. (2019a). Transported pdf simulation of turbulent $\mathrm{CH}_{4} / \mathrm{H}_{2}$ flames under MILD conditions with particle-level sensitivity analysis. Proc. Combust. Inst. 37, 4487-4495. doi: 10.1016/j.proci.2018.05.167

Wang, Y., Jain, A., and Kulatilaka, W. (2019b). CO imaging in piloted liquid-spray flames using femtosecond two-photon LIF. Proc. Combust. Inst. 37, 1305-1312. doi: 10.1016/j.proci.2018.05.016

Wang, Y., Makwana, A., Iyer, S., Linevsky, M., Santoro, R. J., Litzinger, T. A., et al. (2018). Effect of fuel composition on soot and aromatic species distributions in laminar, co-flow flames. part 1. non-premixed fuel. Combust. Flame 189, 443-455. doi: 10.1016/j.combustflame.2017.08.011

Watson, K., Lyons, K., Carter, C., and Donbar, J. (2002). Simultaneous twoshot $\mathrm{CH}$ planar laser-induced fluorescence and particle image velocimetry measurements in lifted $\mathrm{CH}_{4} /$ air diffusion flames. Proc. Combust. Inst. 29, 1905-1912. doi: 10.1016/S1540-7489(02)80231-0

Watson, K., Lyons, K., Donbar, J., and Carter, C. (2000). Simultaneous Rayleigh imaging and $\mathrm{CH}$-PLIF measurements in a lifted jet diffusion flame. Combust. Flame 123, 252-265. doi: 10.1016/S0010-2180(00)00133-4

$\mathrm{Wu}, \mathrm{Z}$., Masri, A. R., and Bilger, R. W. (2006). An experimental investigation of the turbulence structure of a lifted $\mathrm{H}_{2} / \mathrm{N}_{2}$ jet flame in a vitiated co-flow. Flow Turb. Combust. 76, 61-81. doi: 10.1007/s10494-005-9006-2

Yamasaki, Y., and Tezaki, A. (2005). Non-linear pressure dependence of astate fluorescence lifetime of formaldehyde. Appl. Phys. B 80, 791-795. doi: 10.1007/s00340-005-1798-1

Yao, M., Zheng, Z., and Liu, H. (2009). Progress and recent trends in homogeneous charge compression ignition (HCCI) engines. Prog. Energy Combust. Sci. 35, 398-437. doi: 10.1016/j.pecs.2009.05.001

Ye, J., Medwell, P. R., Dally, B. B., and Evans, M. J. (2016). The transition of ethanol flames from conventional to MILD combustion. Combust. Flame 171, 173-184. doi: 10.1016/j.combustflame.2016.05.020

Ye, J., Medwell, P. R., Evans, M. J., and Dally, B. B. (2015). "Quantitative Rayleigh temperature imaging in turbulent flameames of prevaporised n-heptane," in 7 th Australian Conference on Laser Diagnostics in Fluid Mechanics and Combustion (Melbourne, VIC).

Ye, J., Medwell, P. R., Evans, M. J., and Dally, B. B. (2017). Characteristics of turbulent n-heptane jet flames in a hot and diluted coflow. Combust. Flame 183, 330-342. doi: 10.1016/j.combustflame.2017.05.027

Ye, J., Medwell, P. R., Kleinheinz, K., Evans, M. J., Dally, B. B., and Pitsch, H. G. (2018). Structural differences of ethanol and DME jet flames in a hot diluted coflow. Combust. Flame 192, 473-494. doi: 10.1016/j.combustflame.2018.02.025

Yoo, C. S., Richardson, E. S., Sankaran, R., and Chen, J. H. (2011). A DNS study on the stabilization mechanism of a turbulent lifted ethylene jet flame in highly-heated coflow. Proc. Combust. Inst. 33, 1619-1627. doi: 10.1016/j.proci.2010.06.147

Yuan, R. (2015). Measurements in swirl-stabilised spray flames at blow-off. (Ph.D. thesis). University of Cambridge, Cambridge, United Kingdom.

Conflict of Interest: The authors declare that the research was conducted in the absence of any commercial or financial relationships that could be construed as a potential conflict of interest.

Copyright $\odot 2019$ Evans and Medwell. This is an open-access article distributed under the terms of the Creative Commons Attribution License (CC BY). The use, distribution or reproduction in other forums is permitted, provided the original author(s) and the copyright owner(s) are credited and that the original publication in this journal is cited, in accordance with accepted academic practice. No use, distribution or reproduction is permitted which does not comply with these terms. 